\title{
Adriana de Oliveira Mukai
}

\section{Análise espacial da mortalidade perinatal no \\ Vale do Paraíba - São Paulo - Brasil}

(2004-2008)

Tese apresentada à Faculdade de Medicina da Universidade de São Paulo para obtenção do Título de Doutor em Ciências.

Programa de Pediatria

Orientadora: Prof ${ }^{a}$. Dr ${ }^{a}$. Vera Lúcia Jornada Krebs Co-orientador: Prof. Dr. Luiz Fernando Costa Nascimento 


\section{Adriana de Oliveira Mukai}

\section{Análise espacial da mortalidade perinatal no \\ Vale do Paraíba - São Paulo - Brasil}

(2004-2008)

Tese apresentada à Faculdade de Medicina da Universidade de São Paulo para obtenção do Título de Doutor em Ciências.

Programa de Pediatria

Orientadora: Prof ${ }^{a}$. Dr ${ }^{a}$. Vera Lúcia Jornada Krebs Co-orientador: Prof. Dr. Luiz Fernando Costa Nascimento

(Versão corrigida. Resolução CoPGr 5890, de 20 de dezembro de 2010. A versão original está disponível na Biblioteca FMUSP) 
Dados Internacionais de Catalogação na Publicação (CIP)

Preparada pela Biblioteca da

Faculdade de Medicina da Universidade de São Paulo

Creprodução autorizada pelo autor

Mukai, Adriana de Oliveira

Análise espacial da mortalidade perinatal no Vale do Paraíba - São Paulo Brasil (2004-2008) / Adriana de Oliveira Mukai. -- São Paulo, 2012.

Tese(doutorado)--Faculdade de Medicina da Universidade de São Paulo.

Programa de Pediatria.

Orientadora: Vera Lúcia Jornada Krebs.

Co-orientador: Luiz Fernando Costa Nascimento.

Descritores: 1.Mortalidade perinatal 2.Mortalidade fetal 3.Mortalidade neonatal precoce 4.Mortalidade infantil 5.Natimorto 6.Sistemas de informação geográfica 7.Estudos ecológicos 8.Distribuição espacial da população

USP/FM/DBD-220/12 


\section{Dedicatória}

Ao meu companheiro Jaques (in memoriam), pelos anos maravilhosos que vivemos juntos e por me ensinar a viver a vida de uma forma mais alegre, leve e mágica.

À minha filha Marina, como estímulo às suas futuras realizações.

Aos meus pais e irmãos, incentivadores, generosos e amigos.

Aos amigos. 


\section{AGRADECIMENTOS}

A Deus, por me dar forças para seguir sempre em frente.

À Prof ${ }^{\mathrm{a}}$. Dr ${ }^{\mathrm{a}}$. Vera Lúcia Jornada Krebs, por executar com excelência a orientação desta tese, com valorosos comentários e observações críticas. Sou profundamente grata por essa orientação que ultrapassa a tese e deixa a recordação dos momentos sempre agradáveis que passamos juntas e do carinho nos momentos de dificuldade e de dor.

Ao Prof. Dr. Luiz Fernando Costa Nascimento, cuja participação foi essencial para realização desta tese, contribuindo com todo o seu conhecimento em análise espacial. Agradeço a toda sua disponibilidade e amizade.

Ao Prof. Dr. Ciro João Bertoli, pelo incentivo em todos os momentos e pelo grande exemplo para todos no exercício da Pediatria.

Aos Professores Edna Maria de Albuquerque Diniz, Joaquim Carlos Rodrigues e Rossana Pulcineli Vieira Francisco, que muito contribuíram com suas sugestões na etapa de Qualificação desta tese. 


\section{NORMALIZAÇÃO ADOTADA}

Esta dissertação ou tese está de acordo com as seguintes normas, em vigor no momento desta publicação:

Referências: adaptado de International Committee of Medical Journals Editors (Vancouver).

Universidade de São Paulo. Faculdade de Medicina. Divisão de Biblioteca e Documentação. Guia de apresentação de dissertações, teses e monografias. Elaborado por Anneliese Carneiro da Cunha, Maria Julia de A. L. Freddi, Maria F. Crestana, Marinalva de Souza Aragão, Suely Campos Cardoso Valéria Vilhena. 3a ed. São Paulo: Divisão de Biblioteca e Documentação; 2011.

Abreviaturas dos títulos dos periódicos de acordo com List of Journals Indexed in Index Medicus. 


\section{SUMÁRIO}

\section{LISTA DE TABELAS}

LISTA DE FIGURAS

RESUMO

SUMMARY

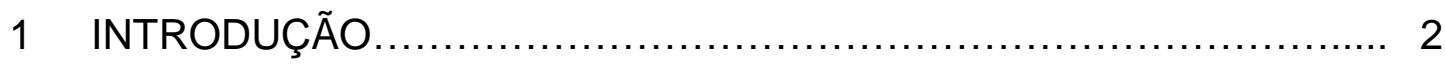

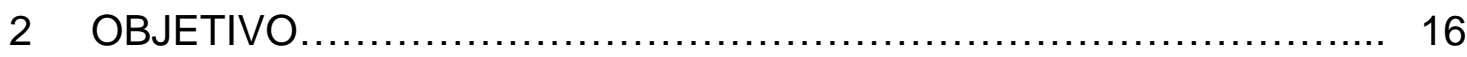

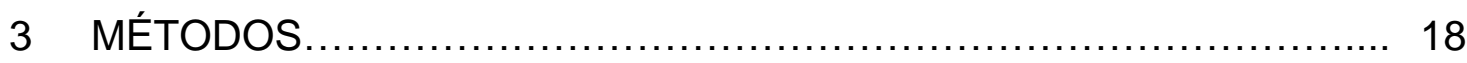

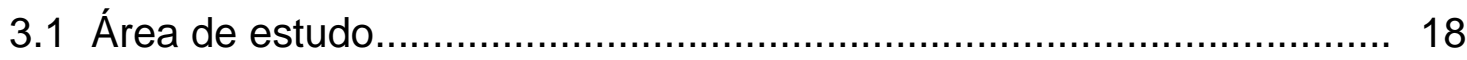

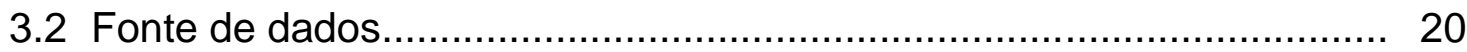

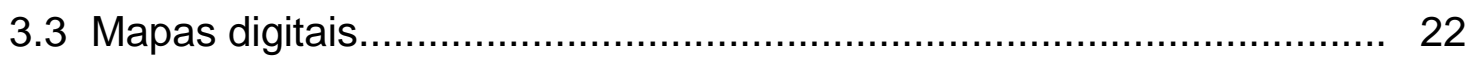

3.4 Análise de dados.......................................................................... 23

3.5 Análise espacial de dados de áreas - técnicas de autocorrelação

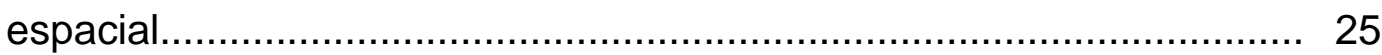

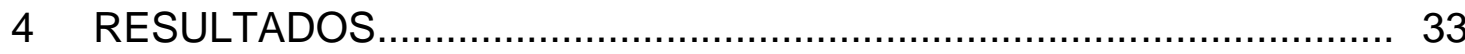

5 DISCUSSÃO .......................................................... 50

5.1 Mortalidade perinatal................................................................... 53

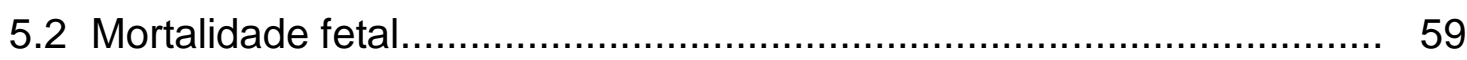

5.3 Mortalidade neonatal precoce ........................................................... 62

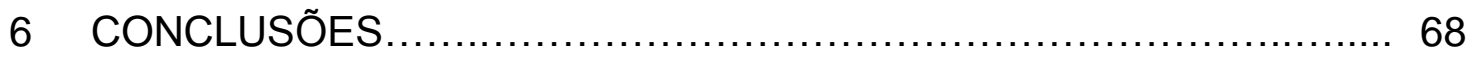

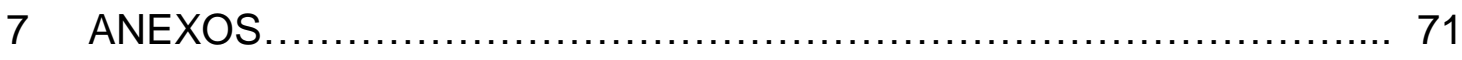

8 REFERÊNCIAS .......................................................... 77 


\section{LISTA DE TABELAS}

Tabela 1 Mortalidade perinatal no Vale do Paraíba, São Paulo - Brasil (2004-2008).

Tabela 2 Coeficientes de mortalidade fetal, neonatal precoce e perinatal, por 1000 nascimentos, no Vale do Paraíba, São Paulo - Brasil (2004-2008)

Tabela 3 Índices de Moran dos coeficientes de mortalidade fetal, neonatal precoce e perinatal por 1000 nascimentos, no Vale do Paraíba (SP), 2004-2008.

Tabela 4 Índices de Moran dos coeficientes de mortalidade fetal e variáveis estudadas por 1000 nascimentos, no Vale do Paraíba (SP), 2004-2008.

Tabela 5 Índices de Moran dos coeficientes de mortalidade neonatal precoce e variáveis estudadas, por $1000 \mathrm{NV}$, no Vale do Paraíba (SP), 2004-2008.

Tabela 6 Índices de Moran do coeficiente de mortalidade perinatal e variáveis estudadas por 1000 nascimentos, no Vale do Paraíba (SP), 2004-2008.

Tabela 7 Correlação entre coeficientes de mortalidade fetal, neonatal precoce e perinatal (2004-2008) e IPRS (2006) no Vale do Paraíba - SP. 


\section{LISTA DE FIGURAS}

Figura 1 Distribuição de casos de hepatite A no município de Macapá de 1999 a 2003.

Figura 2 Olinda: taxa média de incidência de tuberculose no período 19962000, e média de moradores por domicílio em 2000, segundo setores censitários.

Figura 3 Mapa da posição do Vale do Paraíba no Brasil.

Figura 4 Municípios do Vale do Paraíba, com a Rodovia Presidente Dutra em destaque

Figura 5 Janela do Programa TerraView mostrando mapa do Vale do Paraíba

Figura 6 Janela do Programa TerraView para cálculo do índice de Moran global.

Figura 7 Distribuição dos coeficientes de mortalidade neonatal precoce, tardia e total em cidades do Vale do Paraíba - 1999 a 2001

Figura 8 Matriz de vizinhança espacial por adjacência e Taxas de Mortalidade Infantil (/1000 Nascidos Vivos)

Figura 9 Diagrama de espalhamento de Moran.

Figura 10 Distribuição dos municípios do Vale do Paraíba (SP), segundo prioridade de intervenção, segundo o número de internações por pneumonia em menores de um ano de idade.

Figura 11 Distribuição espacial do coeficiente de mortalidade fetal, por 1000 nascimentos, no Vale do Paraíba (SP), 20042008

Figura 12 Distribuição espacial do coeficiente de mortalidade neonatal precoce, por $1000 \mathrm{NV}$, no Vale do Paraíba (SP), 20042008. 
Figura 13 Distribuição espacial do coeficiente perinatal, por 1000 nascimentos, no Vale do Paraíba (SP), 20042008.

Figura 14 Distribuição espacial do coeficiente de mortalidade fetal com representação em gráfico de barras para idade da gestante, por 1000 nascimentos, no Vale do Paraíba (SP), 20042008.

Figura 15 Distribuição espacial do coeficiente de mortalidade neonatal precoce com representação em gráfico de barras para idade materna, por 1000 NV, no Vale do Paraíba (SP), 20042008.

Figura 16 Distribuição espacial do coeficiente de mortalidade neonatal precoce com representação em gráfico de barras para tipo de parto, por 1000 NV, no Vale do Paraíba (SP), 20042008

Figura 17 Distribuição espacial do coeficiente de mortalidade neonatal precoce com representação em gráfico de barras para escolaridade materna, por $1000 \mathrm{NV}$, no Vale do Paraíba (SP), 2004-2008.

Figura 18 Distribuição espacial do coeficiente de mortalidade neonatal precoce com representação em gráfico de barras para idade gestacional, por 1000 NV, no Vale do Paraíba (SP), 20042008

Figura 19 Distribuição espacial do coeficiente de mortalidade perinatal com representação em gráfico de barras para idade materna, por 1000 nascimentos, no Vale do Paraíba (SP), 2004 2008.

Figura 20 Distribuição espacial do Ìndice Paulista de Responsabilidade Social (IPRS) no Vale do Paraíba (SP) no ano de 2006. 
Figura 21 Representação em box map do Diagrama de Espalhamento de Moran da mortalidade perinatal no Vale do Paraíba-SP (20042008).

Figura 22 Representação em box map do Diagrama de Espalhamento de Moran da mortalidade neonatal precoce no Vale do Paraíba-SP (2004-2008).

Figura 23 Representação em box map do Diagrama de Espalhamento de Moran da mortalidade fetal no Vale do Paraíba-SP (20042008) 
RESUMO 
Mukai AO. Análise espacial da mortalidade perinatal no Vale do Paraíba, São Paulo - Brasil (2004-2008) [tese]. São Paulo: Faculdade de Medicina, Universidade de São Paulo; 2012. 90 p.

OBJETIVO: Visualizar padrões espaciais de mortalidade perinatal e identificar os municípios com prioridade para intervenção no Vale do Paraíba, São Paulo, Brasil. MÉTODOS: Trata-se de estudo ecológico e exploratório utilizando técnica de geoprocessamento com dados do Departamento de Informática do Sistema Único de Saúde sobre mortalidade perinatal no Vale do Paraíba nos anos de 2004 a 2008. Foram obtidas taxas por 1.000 nascimentos e, a partir das distribuições dessas, foram criados mapas temáticos. Foi utilizado o índice de Moran, que estima autocorrelação espacial e foram identificados os municípios com alta prioridade de intervenção pelo diagrama de espalhamento de Moran, representado em forma de box map. Foi utilizado o coeficiente de correlação de Spearman para estudar a variável social IPRS (Índice Paulista de Responsabilidade Social) dos municípios estudados e o coeficiente de mortalidade perinatal. RESULTADOS: No período estudado foram incluídos 141.293 nascidos vivos, com 2244 óbitos perinatais, coeficiente médio de mortalidade de 20,4 (DP 6,8) e mediana de 18,9. O índice de Moran identificou dependência espacial entre os municípios analisados quanto à mortalidade neonatal precoce $(p<0,05)$, sendo que para a mortalidade fetal e perinatal não houve significância estatística, apesar do mapa de distribuição espacial do coeficiente de mortalidade perinatal ter identificado um aglomerado de municípios com coeficientes mais elevados. Nas variáveis estudadas observamos contribuição maior da gestação na adolescência na mortalidade perinatal. Foram identificados cinco municípios com alta prioridade para intervenções. CONCLUSÃO: A análise espacial foi um instrumento útil para identificar os municípios onde há necessidade de intervenção em relação à mortalidade perinatal.

Descritores: Mortalidade perinatal; Mortalidade fetal; Mortalidade neonatal precoce; Mortalidade infantil; Natimorto; Sistemas de informação geográfica; Estudos ecológicos; Distribuição espacial da população. 
SUMMARY 
Mukai AO. Spatial analysis of perinatal mortality in the Paraiba Valley, Sao Paulo - Brazil (2004-2008) [thesis]. Faculty of Medicine, University of Sao Paulo, SP (Brazil); 2012.

OBJECTIVE: This study aims to analyze spatial standards of perinatal mortality and identify the priority cities for intervention in the Paraiba Valley, state of Sao Paulo, Brazil. METHODS: This is an ecological and exploratory study using a technique of geoprocessing with data of the Informatics Department of the Single Health System on perinatal mortality in the years of 2004 to 2008. Rates per 1000 births were obtained and, starting from the distribution of these rates, thematic maps were created. The global Moran index, which estimates the spatial autocorrelation was used, and the cities with high priority for intervention were identified according to the Moran scattering diagram, represented in box map. The Spearman correlation coefficient was used to study the socioeconomic variable IPRS (Social Responsibility Index of Sao Paulo State) of the cities studied and the perinatal mortality coefficient. RESULTS: During the study period, 141.293 live births were included, with 2244 perinatal deaths, with average coefficient of 20,4 and median of 18,9 . The global Moran index was $0,24(p<0,05)$ for early neonatal mortality, demonstrating a spatial autocorrelation among the cities for these coefficient, while fetal and perinatal mortality have no statistical significance, despite the spatial distribution map of perinatal mortality coefficient have identified a cluster of cities with higher coefficients. In the variables studied, we observed a greater contribution of the variable adolescent pregnant. Five cities deserving special attention for future interventions were identified. CONCLUSIONS: The spatial analysis was a useful tool in identifying the cities in which an intervention is necessary regarding the perinatal mortality.

Key-words: Perinatal mortality; Fetal mortality; Early neonatal mortality; Infant mortality; Stillbirth; Geographic information systems; Ecological studies; Residence characteristics. 
1. INTRODUÇÃO 


\section{INTRODUÇÃO}

Os coeficientes de mortalidade fetal, perinatal e neonatal são amplamente utilizados como indicadores das condições de saúde e da qualidade da assistência obstétrica e neonatal. As melhorias na atenção à saúde da mulher e da criança na última década contribuíram para a diminuição da mortalidade materna e de crianças menores de cinco anos. No entanto, de acordo com dados da World Health Organization (WHO), com relação à mortalidade fetal e neonatal o impacto destas medidas foi menor (UNICEF, 2009; WHO, 2011). A mortalidade fetal é um importante problema de saúde pública, muitas vezes esquecido, em parte devido ao menor conhecimento de sua incidência, de sua etiologia e de estratégias para prevenção (MacDorman \& Kirmeyer, 2009; MacDorman, 2011).

Atualmente, ocorrem aproximadamente 3,1 milhões de óbitos neonatais e 2,6 milhões de óbitos fetais em todo 0 mundo. Aproximadamente $38 \%$ dos óbitos em crianças com idade inferior a cinco anos ocorrem no período neonatal e $75 \%$ destes nos primeiros sete dias de vida (WHO, 2011).

Informações fornecidas por registros de óbitos evidenciam declínio do número de natimortos de $1,1 \%$ ao ano mundialmente, com diminuição do total de 3,0 milhões de óbitos em 1995 pra 2,6 milhões em 2009. O coeficiente de mortalidade fetal diminuiu de 22,1 para 18,9 óbitos/1000 nascimentos, sendo que $76,2 \%$ desses ocorrem no sul da Ásia e na África 
sub-Saariana. Estima-se que 66\% (1,8 milhões de natimortos) ocorram em apenas 10 países: Afeganistão, Bangladesh, China, República Democrática do Congo, Etiópia, Índia, Indonésia, Nigéria, Paquistão e Tanzânia (Cousens et al., 2011; WHO, 2011). No Brasil o coeficiente de mortalidade fetal é de 10,4/ 1000 nascimentos (DATASUS, 2012).

De acordo com dados da Organização Mundial de Saúde (OMS), a mortalidade neonatal (0-28 dias de vida) diminuiu globalmente de 4,4 milhões de óbitos em 1990 para 3,1 milhões em 2010. O coeficiente de mortalidade neonatal passou de 32,0 para 23,0 óbitos/1000 nascidos vivos (NV), sendo este progresso considerado pequeno e de distribuição desigual (WHO, 2011). Em nosso País esse coeficiente é de 9,7 óbitos/1000 NV (DATASUS, 2012).

Os coeficientes de mortalidade são os indicadores de saúde mais tradicionais e constituem uma importante fonte para avaliar as condições de saúde da população. A taxa ou coeficiente de mortalidade infantil compreende o número de óbitos de menores de um ano de idade, por mil nascidos vivos, na população residente em determinado espaço geográfico, no ano considerado. A mortalidade infantil compreende a mortalidade neonatal precoce (óbitos de zero a 6 dias de vida completos); a mortalidade neonatal tardia (óbitos de 7 a 27 dias de vida completos) e a mortalidade pós-neonatal (óbitos de 28 a 364 dias de vida completos) (Brasil. Ministério da Saúde, 2009).

Óbito fetal é a morte do produto da concepção ocorrida antes da sua completa expulsão ou extração do organismo materno, independentemente 
do tempo de gestação. $O$ coeficiente de mortalidade perinatal compreende os óbitos fetais (com mais de 22 semanas de gestação ou 154 dias) mais os óbitos neonatais precoces (Brasil. Ministério da Saúde, 2004; WHO, 2006).

A redução da mortalidade infantil representa um desafio e uma meta almejada pelas instituições governamentais e pela sociedade como um todo. Esta meta está incluída nos Objetivos de Desenvolvimento do Milênio apresentados na Declaração do Milênio das Nações Unidas com a participação de 191 países membros no dia oito de setembro de 2000. Acabar com a fome e a miséria, fornecer educação básica de qualidade, promover a igualdade entre os sexos, reduzir a mortalidade infantil, melhorar a saúde das gestantes, combater a AIDS, a malária e outras doenças, fomentar novas bases para o desenvolvimento sustentável e estimular o engajamento de todos os interessados em participar destas ações são os oito objetivos. A Organização da Nações Unidas (ONU) pretende alcançálos até 2015 e, no Brasil estes 8 Objetivos incluem 24 metas (Brasil. PNDU, 2000)

Apesar da diminuição observada nos últimos quinze anos, a mortalidade infantil no Brasil ainda é alta. O coeficiente atual de 22 óbitos em crianças menores de 5 anos/1000 NV é considerado incompatível com o desenvolvimento do País, ocupando a $107^{a}$ posição na classificação mundial, juntamente com o Equador e a China. Os melhores índices estão na Alemanha, Japão e Suécia, com três a quatro óbitos em crianças menores de 5 anos/1000 NV (UNICEF, 2009). 
Taxas diferentes são observadas nas cinco Regiões do Brasil, sendo que o Nordeste apresenta a maior taxa, enquanto as menores taxas são observadas nas Regiões Sul e Sudeste (UNICEF, 2007; Brasil. Ministério da Saúde, 2009).

No Brasil, o coeficiente de mortalidade infantil é semelhante àquele observado nos países desenvolvidos no final da década de 60. Esses países apresentaram uma redução simultânea da mortalidade pós-neonatal e neonatal. Em nosso País, embora tenha ocorrido diminuição importante da mortalidade infantil, houve aumento do componente neonatal precoce nas últimas décadas. Essas mortes precoces são decorrentes de um conjunto de fatores biológicos, sociais, culturais e de falhas do sistema de saúde, podendo ser consideradas evitáveis, em sua maioria (Brasil. Ministério da Saúde, 2009).

No ano de 2010 encontramos as seguintes causas de óbito no Painel de Monitoramento da Mortalidade Infantil e Fetal, segundo a Classificação Internacional de Doenças (CID 10): Algumas afecções originadas no período perinatal (61\%); malformações congênitas, deformidades e anomalias cromossômicas (19\%); algumas doenças infecciosas e parasitárias (5\%); Doenças do aparelho respiratório (4\%) e sintomas, sinais e achados anormais ao exame clínico e laboratorial (3\%). O restante (7\%) corresponde a outras causas em menores frequências (Brasil. Ministério da Saúde, 2012).

Nos países em desenvolvimento, a redução da mortalidade infantil continua a ser um dos principais objetivos dos programas de saúde pública e pouca atenção é dada à mortalidade fetal. As causas da natimortalidade e a 
frequência de nascidos vivos prematuros representam duas áreas importantes para investigação e intervenção de políticas públicas (Woods, 2008). Em muitos países desenvolvidos, as taxas de mortalidade fetal superam as de mortalidade infantil e os óbitos perinatais são a grande preocupação de obstetras e pediatras (Woods, 2008; MacDorman, 2011).

Utilizam-se os indicadores de saúde para demonstrar o panorama da saúde populacional e permitir comparações na população. Entre esses indicadores estão incluídos: mortalidade, morbidade, nutrição, crescimento e desenvolvimento, condições socioeconômicas e saúde ambiental. Podem ser expressos como valores absolutos, frequentemente usados na monitoração da ocorrência de doenças infecciosas. Entretanto, para comparar a frequência de uma doença entre diferentes grupos, os dados são expressos em forma de taxas ou coeficientes (Menezes, 2001).

A mortalidade perinatal tem sido recomendada como o indicador mais adequado para a análise da assistência obstétrica e neonatal, propiciando visualização do problema e identificação de ações de prevenção com o objetivo de reduzir a morte fetal e neonatal precoce evitável (Brasil. Ministério da Saúde, 2009). Portanto, o conceito de mortalidade perinatal constitui um indicador mais fiel dos fatores vinculados ao processo de gestação, enquanto as influências ambientais são de grande importância no estudo da mortalidade neonatal tardia. O detalhamento de ambos, óbitos fetais e neonatais precoces é importante para os programas que visam redução da mortalidade. 
Dados disponibilizados pelo Ministério da Saúde mostram que, entre os anos de 2004 e 2008, ocorreram no Brasil 144.307 óbitos fetais e 243.217 óbitos em crianças abaixo de um ano, sendo que $51,5 \%$ ocorreram no período neonatal precoce, $15,6 \%$ no período neonatal tardio e $32,9 \%$ no período pós-neonatal. No mesmo período no Estado de São Paulo ocorreram 19.671 óbitos no período neonatal precoce e 24.257 óbitos fetais (DATASUS, 2011a).

No início da década de 1970 foi criado o Sistema de Informação de Mortalidade (SIM), representando um avanço na concepção dos sistemas de informações para vigilância epidemiológica, padronizado para coleta de dados da declaração de óbito (DO), segundo normas propostas pela Organização Mundial de Saúde. Possibilitou-se assim o início do processamento eletrônico de dados.

No final da década de 1980 foi implementada uma Declaração de Nascido Vivo (DN), padronizada para todo o território nacional como documento base do Sistema de Informações Sobre Nascidos Vivos (SINASC). A informação sobre nascidos vivos é indispensável para a gestão dos serviços de saúde, sendo utilizada nas atividades de planejamento da assistência ao parto e ao recém-nascido, assim como na construção de indicadores de saúde e demográficos. A fonte tradicional de dados é o registro civil, documento este que desde 1997 ficou isento de quaisquer taxas de pagamento, diminuindo assim o sub-registro.

A incorporação da tecnologia de processamento eletrônico de dados pelo Departamento de Informática do Sistema Único de Saúde (DATASUS) 
propiciou maior agilidade no acesso às informações contidas nesses sistemas, bem como a disponibilização dessas informações (Brasil. Ministério da Saúde, 2009).

A maioria dos estudos sobre mortalidade perinatal e neonatal é do tipo analítico observacional, como estudos transversais, de coorte e de casocontrole, com utilização de regressão logística para identificação de fatores de risco associados ao óbito fetal (Matijasevich et al., 2005; Fonseca \& Coutinho, 2010; Oliveira et al., 2010), neonatal (Sarinho et al., 2001; Araújo et al., 2007; Carvalho et al., 2007; Schoeps et al., 2007; Paulucci \& Nascimento, 2007; Barros et al., 2008;) e perinatal (Barros et al., 1987; Aquino et al., 2007). Nesses tipos de estudo a unidade de observação é o indivíduo.

Quando a unidade de observação é um grupo de pessoas temos um estudo analítico observacional do tipo ecológico, onde as fontes de dados podem ser registros de mortalidade, registros de morbidade e dados censitários sobre morbimortalidade e população (Menezes, 2001).

A opção por estudos epidemiológicos do tipo ecológico é adequada para o entendimento da variação do risco de adoecer entre diferentes grupos populacionais. Esse tipo de estudo possibilita a análise da mortalidade perinatal e outros eventos segundo sua distribuição espacial (Morais Neto et al., 2001; Santos \& Noronha, 2001; Nascimento et al., 2007; Lima et al., 2008; Mukai et al., 2009; Nascimento \& Medeiros, 2012).

O desenvolvimento de tecnologias para análise de dados no espaço geográfico oferece novas possibilidades para o estudo da situação de saúde 
e de suas tendências, possibilitando melhor compreensão de fatores que determinam as condições de vida e o estado de saúde da população. A utilização desses recursos pelo setor de saúde é muito importante no Brasil, onde acentuadas desigualdades se evidenciam nos Estados e nos municípios, bem como no interior destas áreas, sobretudo nos espaços urbanos. Juntamente com essas situações diferenciadas, as transformações demográficas observadas nas últimas décadas modificam a dinâmica de distribuição de doenças e agravos, bem como de demanda e acesso aos serviços.

A visualização dos agravos à saúde, correlacionados aos seus determinantes, constitui ferramenta importante e complementar a outros modelos de análise com este fim. Frente aos enormes desafios para a organização e a atuação do setor de saúde, com crescente necessidade de dados informatizados para análise crítica, a apresentação de sua distribuição na forma espacial poderá ser utilizada pelas instâncias decisórias para medidas de intervenção (Brasil. Ministério da Saúde, 2007).

A Análise Espacial pode ser definida como uma técnica que busca descrever os padrões existentes nos dados espaciais e estabelecer relações de forma quantitativa preferencialmente (Carvalho, 1997). Os objetivos da análise espacial são aprofundar a compreensão dos fenômenos, avaliar evidências de hipóteses a eles relacionadas, ou ainda tentar prever valores em áreas onde as observações não estão disponíveis (Bailey \& Gatrell, 1995). 
Introdução

Cada vez mais, trabalhos vêm sendo desenvolvidos utilizando a abordagem espacial e produzindo análises integradas da associação dos eventos de saúde com variáveis socioambientais, na tentativa de suprir as necessidades do Sistema de Vigilância em Saúde. A análise dos eventos a partir de uma perspectiva ecológica ou populacional possibilita não só a vigilância dos indivíduos de risco, mas também uma visão do risco coletivo, para subsidiar intervenções de saúde pública nos vários grupos sociais, acompanhando as constantes mudanças dos processos sociais (Brasil. Ministério da Saúde, 2007).

As fontes de informação para essas variáveis e as abordagens para a construção desses indicadores variam e vêm sendo objeto de estudos que visam contribuir para superar desigualdades em saúde. Em muitos casos, essas informações são provenientes dos censos demográficos, disponibilizadas no nível dos setores censitários, possibilitando análises para este nível ou níveis mais agregados, como bairros, distritos e municípios. No caso dos indicadores ambientais especificamente, as informações são obtidas junto a institutos municipais ou estaduais de meio ambiente ou planejamento urbano, provenientes de levantamentos de campo, levantamentos aéreos ou de imagens de satélite.

De acordo com o tipo de evento estudado, algumas técnicas estatísticas são mais apropriadas. Basicamente o evento investigado pode ser representado por dois tipos de dados: atributos de pontos ou atributos de áreas. O tipo mais simples é o de pontos, onde temos a localização pontual 
(coordenada) de algum evento, sendo o mais comum o da residência de um caso de doença, como mostra a Figura 1.

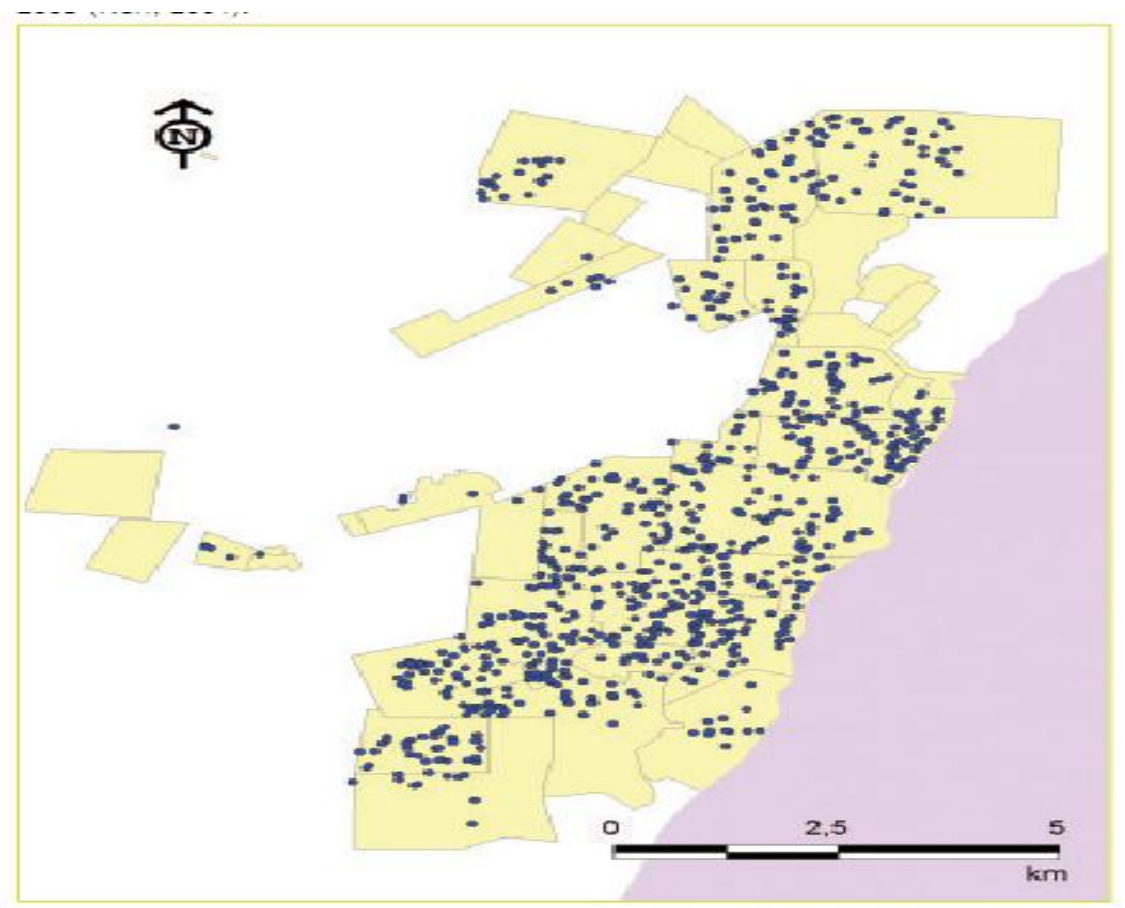

FONTE: Brasil. Ministério da Saúde, 2007, p.35.

Figura 1- Distribuição de casos de hepatite A no município de Macapá de 1999 a 2003

Outro tipo de dado é o proveniente de áreas geográficas com limites definidos, usualmente divisões político-administrativas, como municípios e Estados. Associados a essas áreas tem-se, por exemplo, as contagens de casos ou óbitos de alguma doença ou os indicadores provenientes do censo demográfico, sendo importante observar a escala em que esses dados são coletados e analisados. Dados de áreas são os mais analisados na área da saúde. Em geral, quanto maior a área geográfica, mais heterogênea é a população onde ocorre o evento em estudo. No outro extremo, os setores censitários têm população mais semelhante do ponto de vista socioeconômico e demográfico. Entretanto, quando consideramos áreas 
Introdução

com pequenas populações, os eventos observáveis são mais raros, o que origina excessiva flutuação aleatória dos indicadores e todos os problemas daí decorrentes.

Na Figura 2 encontra-se um mapa temático representando as taxas médias de incidência de tuberculose, segundo setores censitários do Município de Olinda-PE, para o período 1996-2000 e outro representando a média de moradores por domicílio, para estes mesmos setores censitários de Olinda, segundo o Censo Demográfico de 2000. Nos mapas podem ser visualizados vários setores com altas taxas de incidência de tuberculose e com altas concentrações de moradores por domicílio (Brasil. Ministério da Saúde, 2007).
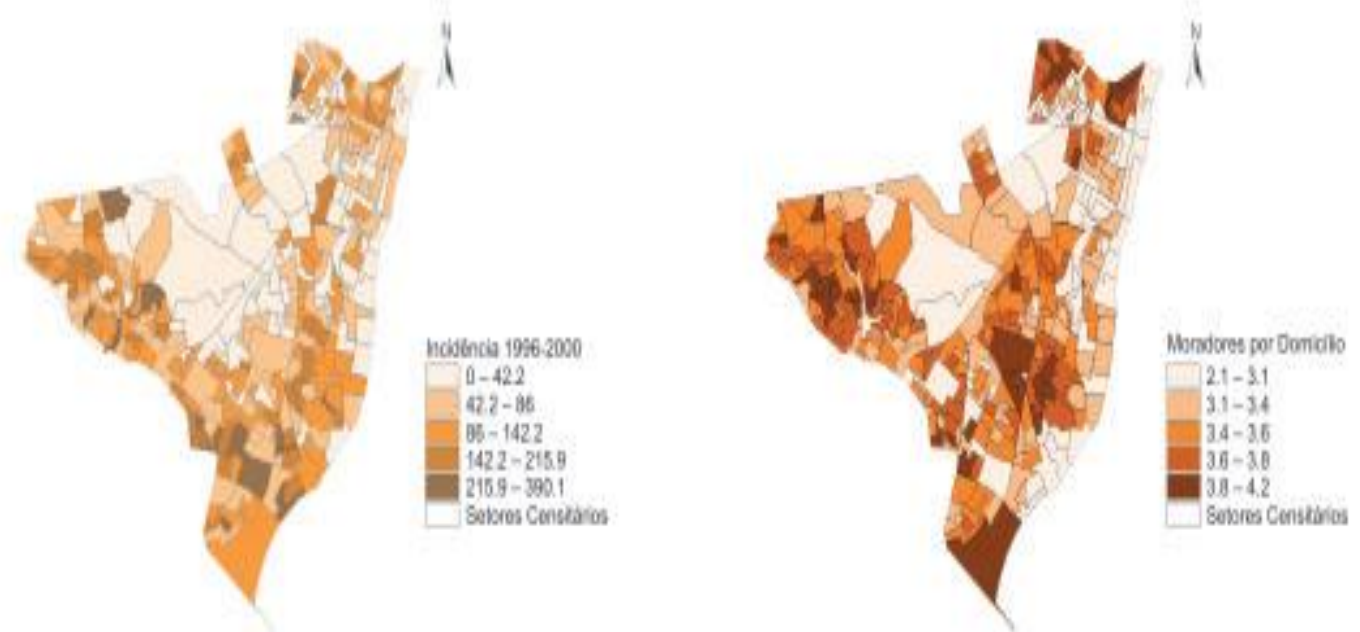

FONTE: Brasil. Ministério da Saúde, 2007, p.17.

Figura 2 - Olinda: taxa média de incidência de tuberculose no período 1996-2000, e média de moradores por domicílio em 2000, segundo setores censitários 
A Estatística Espacial é o ramo da estatística que permite analisar a localização espacial de eventos. A denominação Estatística Espacial constitui uma complementação às técnicas estatísticas comumente utilizadas nos estudos em saúde. Permite a identificação da localização espacial e sua possível importância na análise e interpretação de resultados. Ou seja, além de identificar, localizar e visualizar a ocorrência de fenômenos que se materializam no espaço, tarefas essas possibilitadas pelo uso dos Sistemas de Informações Geográficas (SIG), a Estatística Espacial possibilita modelar a ocorrência de fenômenos distribuídos no espaço, incorporando, por exemplo, os fatores determinantes, a estrutura de distribuição espacial ou a identificação de padrões (Brasil. Ministério da Saúde, 2007).

A Estatística Espacial é aplicada no mapeamento de doenças, nos estudos ecológicos, na identificação de aglomerados espaciais (clusters) e no monitoramento de problemas ambientais. Assim sendo, o uso da análise espacial possibilita a realização de estudos sobre a distribuição dos agravos sejam eles internações hospitalares, coeficientes de incidência, estudo de séries temporais ou óbitos por causas definidas (Morais Neto et al., 2001; Nascimento et al., 2007; Lima et al., 2008; Mukai et al., 2009; Nascimento \& Medeiros, 2012).

A mortalidade perinatal é um indicador importante de avaliação da qualidade da assistência materna e neonatal. Os dados relativos à morbidade e à mortalidade do Estado de São Paulo estão disponíveis na 
rede DATASUS, porém não existem estudos até o momento sobre mortalidade perinatal no Brasil utilizando a técnica de análise espacial.

A hipótese do presente estudo é que a mortalidade perinatal apresente variações de padrão espacial entre os 39 municípios que compõem o Vale do Paraíba e que a análise de sua distribuição neste espaço geográfico, aliada ao conhecimento dos fatores de risco mais frequentes nas áreas de maior mortalidade, sejam úteis para o desencadeamento de intervenções de saúde destinadas à população materno-infantil. 
2. OBJETIVO 


\section{OBJETIVO}

Analisar a distribuição espacial da mortalidade perinatal no Vale do Paraíba, Estado de São Paulo, Brasil e produzir mapas que identifiquem áreas de alto risco para mortalidade perinatal. 
3. MÉTODOS 


\section{MÉTODOS}

Realizou-se um estudo ecológico utilizando técnicas de geoprocessamento de dados agregados por área. A unidade de análise de área foi o Município, sendo que a região de estudo é constituída por 39 municípios. Foram excluídos os quatro municípios do litoral (Caraguatatuba, Ilhabela, São Sebastião e Ubatuba), por estarem afastados do Vale do Paraíba e não apresentarem vizinhança direta com os municípios, devido ao limite natural (Serra do Mar).

\section{1 Área de estudo}

O Vale do Paraíba é uma região situada no leste do Estado de São Paulo (Figura 3), entre as serras da Mantiqueira e do Mar. É cortada pela Rodovia Presidente Dutra, no eixo entre as duas capitais, Rio de Janeiro e São Paulo. É composto de 39 municípios, com população de aproximadamente 2,2 milhões de habitantes, sendo uma das regiões mais industrializadas e urbanizadas do Estado de São Paulo e está representada na Figura 4, com a exclusão dos quatro municípios litorâneos. 


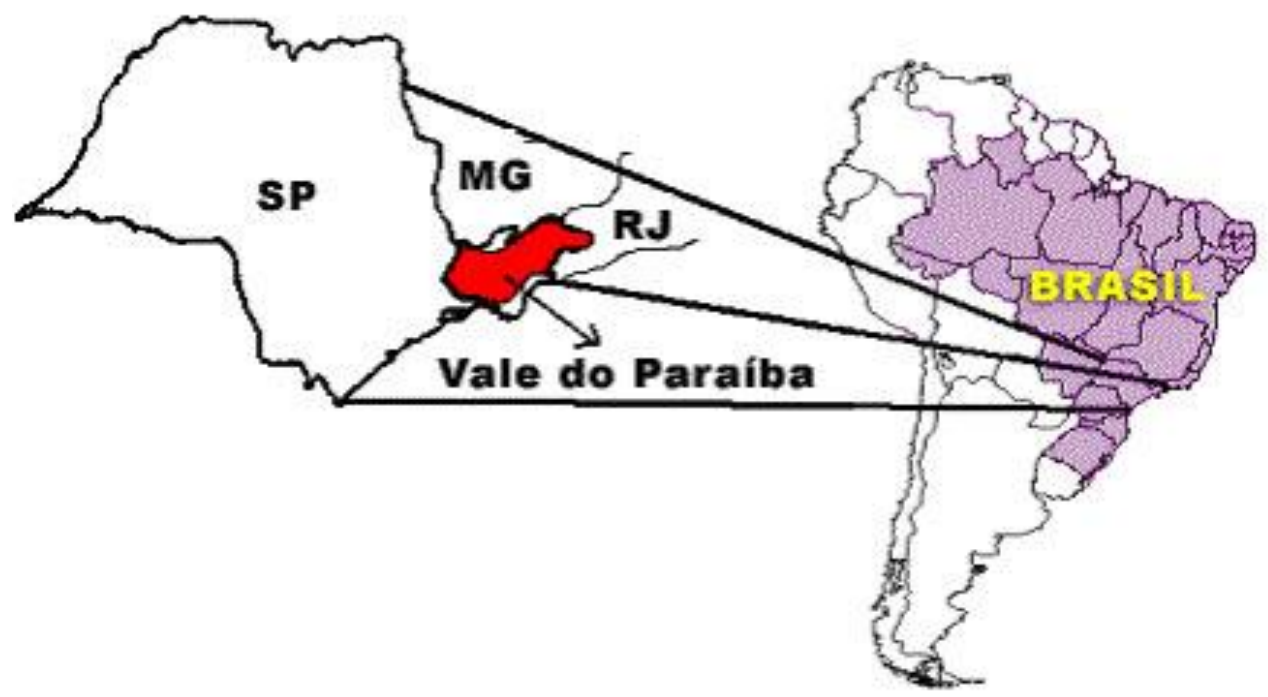

FONTE: Valeverde, 2007.

Figura 3 - Mapa da posição do Vale do Paraíba no Brasil

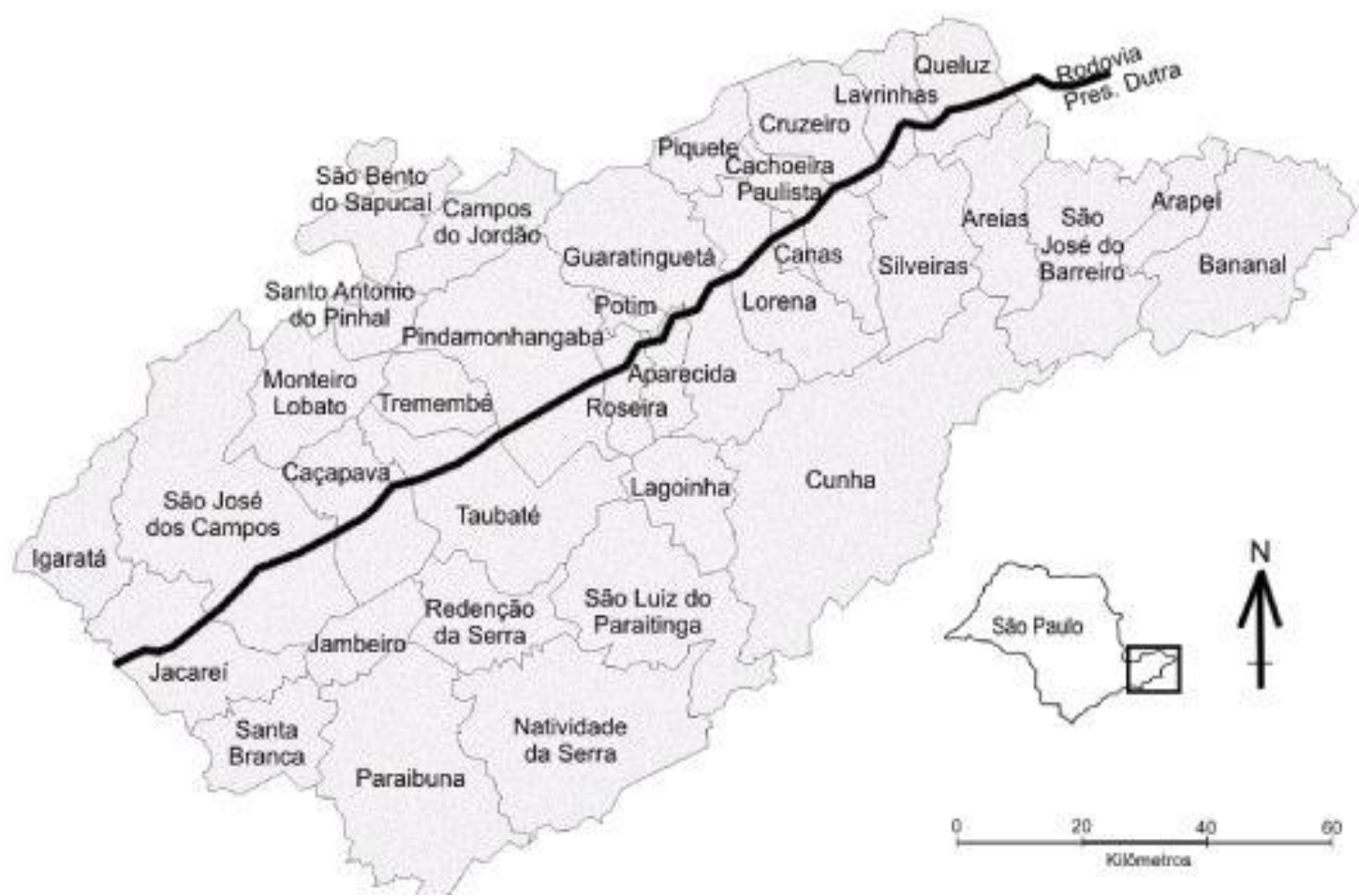

FONTE: Nascimento et al., 2007.

Figura 4 - Municípios do Vale do Paraíba, com a Rodovia Presidente Dutra em destaque 
Segundo dados do Instituto Brasileiro de Geografia e Estatística (IBGE), o Índice de Desenvolvimento Humano (IDH) é maior em municípios situados próximos à Rodovia Presidente Dutra e a maioria destes apresenta economia voltada para a indústria. Os municípios com índices menores de IDH são os que estão afastados da Rodovia e possuem economia com forte influência rural.

\subsection{Fonte de dados}

Os dados referentes à mortalidade perinatal foram obtidos na base do portal DATASUS (http://www.datasus.gov.br) e referem-se aos municípios de residência, o que impede eventuais evasões de óbitos. Foram calculados os coeficientes de mortalidade fetal, neonatal precoce e perinatal. O período analisado corresponde aos anos de 2004, 2005, 2006, 2007 e 2008, dados mais recentes disponíveis na rede e compreende cinco anos, visando evitar flutuações dos dados (DATASUS, 2008).

Há uma defasagem entre dois e três anos para a divulgação das informações nacionais produzidas pelo SINASC, que não é muito diferente daquela observada em outros países, como, por exemplo, as estatísticas de nascimento disponíveis no site do National Center of Health Statistics (Martin et al., 2003). 
As variáveis estudadas foram categorizadas conforme os dados encontrados no Portal DATASUS.

As variáveis referentes aos óbitos fetais foram:

- idade materna: adolescente (entre 10 e 19 anos) e adulta (a partir de 20 anos);

- escolaridade materna: baixa (menor que 7 anos) e alta (8 anos ou mais);

- sexo do feto;

- peso do feto: 500 a 999g, 1000 a $1499 g, 1500$ a $2499 g$, de 2500 a 3999g.

As variáveis estudadas referentes aos óbitos neonatais precoces foram as mesmas citadas acima para idade e escolaridade maternas, mais as seguintes:

- tipo de parto: vaginal ou cesáreo;

- sexo do recém-nascido $(\mathrm{RN})$;

- peso do RN: 500 a 999g, 1000 a 1499g, 1500 a 2499g, de 2500 a $3999 \mathrm{~g}$ e com $4000 \mathrm{~g}$ e mais;

- prematuridade: de 22 a 27 semanas, de 28 a 31 semanas e de 32 a 36 semanas de idade gestacional.

O Índice Paulista de Responsabilidade Social (IPRS) dos municípios estudados do ano de 2006 foi utilizado como variável socioeconômica.

O IPRS é um sistema de indicadores socioeconômicos referidos a cada município do Estado de São Paulo e surgiu em 2002 com a finalidade de subsidiar a formulação e a avaliação de políticas públicas em escala 
municipal. Com o IPRS, a Fundação Sistema Estadual de Análise de Dados (SEADE) procurou criar para o Estado de São Paulo um indicador que utiliza três componentes - renda, escolaridade e longevidade - e que tem a possibilidade de observar mudanças nas condições de vida do município em curto espaço de tempo, atualizar os indicadores para os anos entre os censos demográficos e identificar a situação de cada um dos municípios nas dimensões renda, escolaridade e longevidade. Esse tipo de indicador possibilita melhor conhecimento das condições de vida existentes no município, o que é fundamental no desencadeamento de políticas públicas específicas para municípios com diferentes níveis e padrões de desenvolvimento (SEADE, 2011).

As variáveis selecionadas para composição do IPRS estão no Anexo A. Os critérios adotados para a formação dos grupos de municípios estão no Anexo $\mathrm{B}$ e os respectivos valores dos municípios estudados estão no Anexo C.

\subsection{Mapas digitais}

Foi utilizado o mapa urbano básico digital dos municípios que compreendem o Vale do Paraíba, que foi produzido no Laboratório de Geoprocessamento (LAGEO) do Departamento de Ciências Agrárias da 
Universidade de Taubaté (UNITAU) e adaptado para uso em Sistemas de Informações Geográficas e análise de dados espaciais.

\subsection{Análise de dados}

Os dados foram analisados através do programa de acesso público TerraView 4.0.0 (Figuras 5 e 6), desenvolvido pelo Instituto Nacional de Pesquisas Espaciais (INPE) e disponibilizado no endereço www.dpi.inpe.br/terraview.

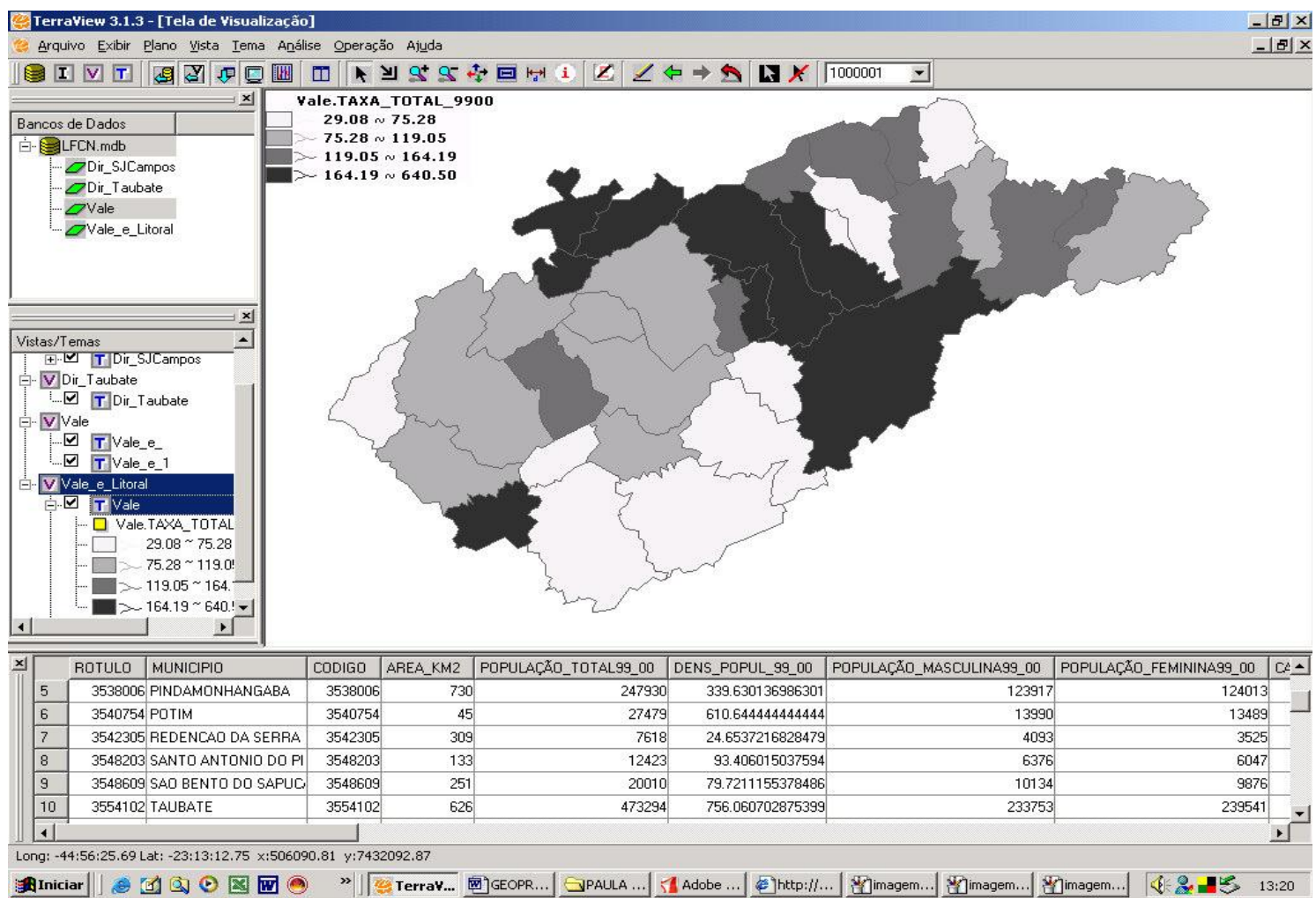

FONTE: TerraView 3.1.3, 2006.

Figura 5 - Janela do Programa TerraView mostrando mapa do Vale do Paraíba 


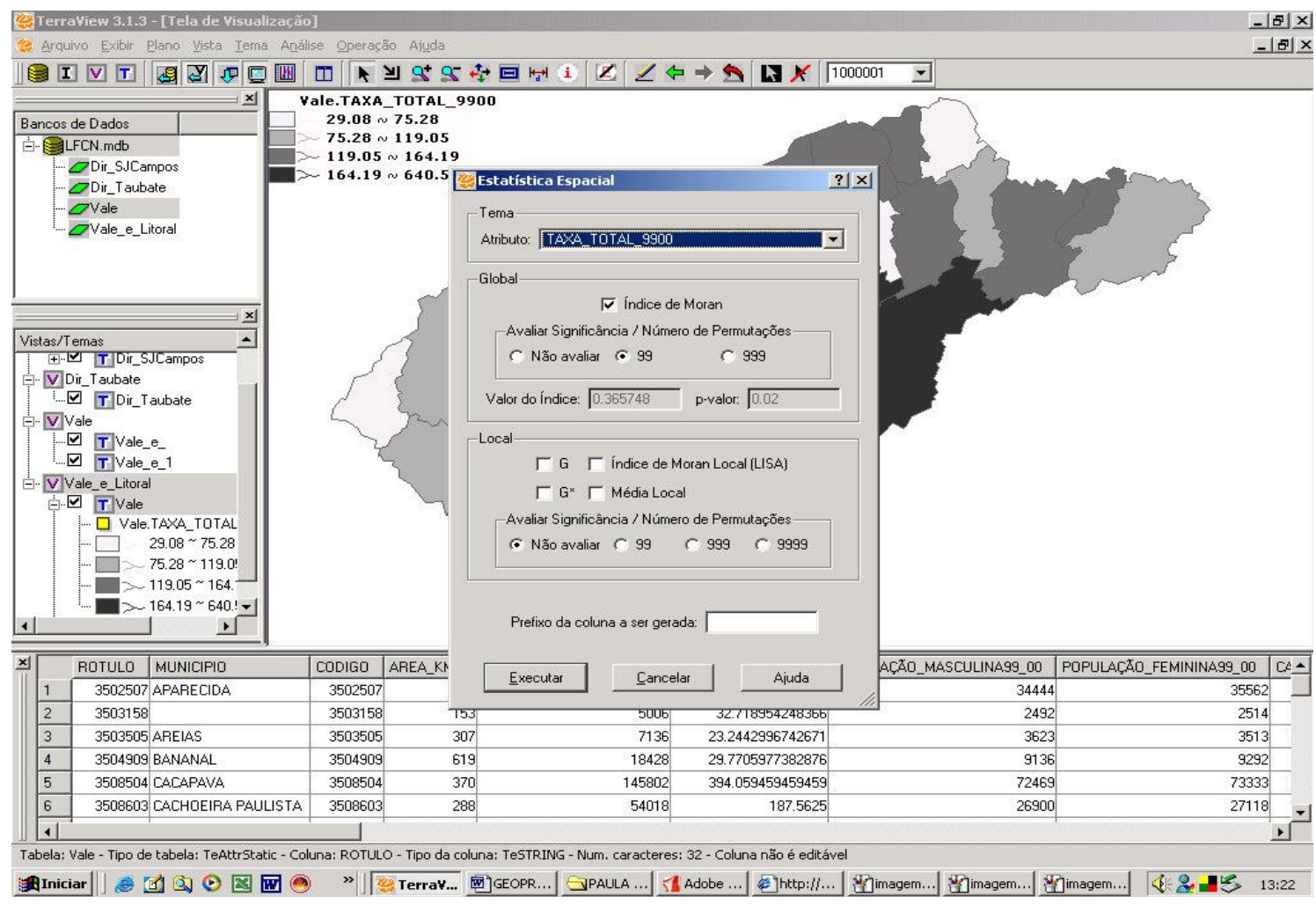

FONTE: TerraView 3.1.3, 2006.

Figura 6 - Janela do Programa TerraView para cálculo do índice de Moran global

Dessa forma foram construídos mapas com os determinados coeficientes de mortalidade estudados por área, sendo agrupados por quartis. Esses mapas possibilitam a visualização da distribuição dos coeficientes de mortalidade e podem ser capazes de identificar aglomerados de cidades com características semelhantes. São definidas áreas delimitadas por linhas ou polígonos. Um exemplo é o mapa de municípios de uma região ou mapa de bairros de uma cidade. Na Figura 7 pode ser observado o resultado do estudo de mortalidade neonatal em cidades de uma região (Nascimento et al., 2007). As regiões mais escuras são as que apresentam taxas mais elevadas, podendo ser observado um aglomerado 
(cluster) para a mortalidade neonatal precoce e total. Este aglomerado representa cidades com mesmas características de mortalidade.

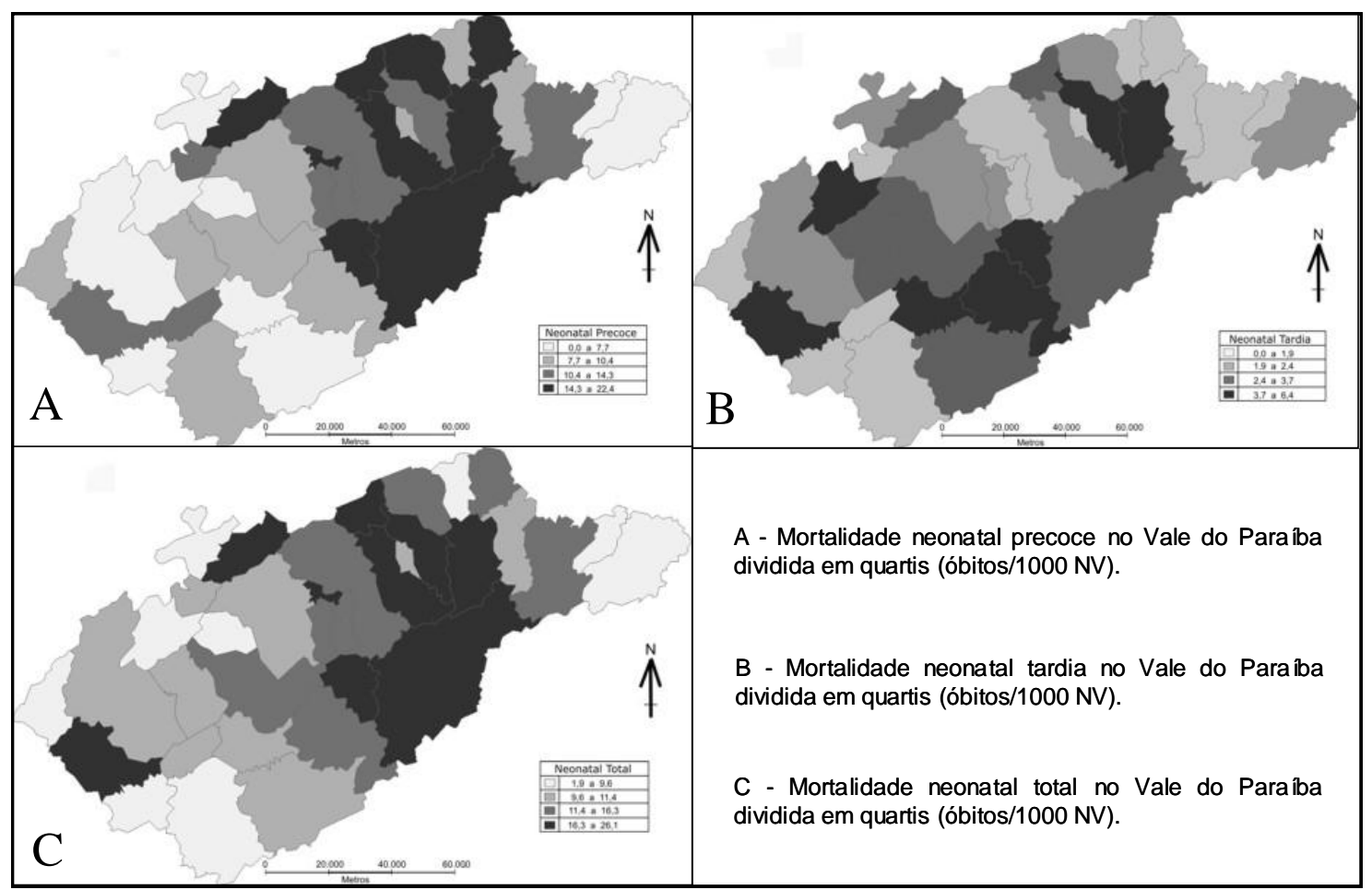

FONTE: Nascimento et al., 2007.

Figura 7 - Distribuição dos coeficientes de mortalidade neonatal precoce, tardia e total em cidades do Vale do Paraíba - 1999 a 2001

3.5 Análise espacial de dados de áreas - técnicas de autocorrelação espacial

a) Índice Global de Moran

Após a construção dos mapas digitais os dados foram analisados utilizando-se técnica de análise espacial de áreas. A estrutura de 
dependência entre os valores observados nas várias áreas do fenômeno em estudo é analisada pela função de autocorrelação espacial.

Autocorrelação mede a correlação da própria variável, e, sendo espacial, no espaço. A correlação de uma variável com ela mesma, medida no mesmo local, será sempre 1 (UM). Entretanto, a correlação de uma variável com ela mesma, porém medida nas áreas vizinhas terá um valor que varia entre -1 e 1 (como qualquer medida de correlação). Quanto mais próximo de 1 (UM), maior a semelhança entre vizinhos - autocorrelação espacial positiva. O valor 0 (ZERO) indica inexistência de correlação, e valores negativos indicam dessemelhança (Cliff \& Ord, 1981; Brasil. Ministério da Saúde, 2007).

Para exemplificar a sua aplicação é necessário utilizar uma matriz de vizinhança, como no exemplo na Figura 8, onde consideramos vizinhos os municípios que partilham de fronteira comum. Nesse caso, a matriz é simétrica: valor 1 (UM) quando são vizinhos e 0 (ZERO) caso contrário. O valor do indicador em estudo, nesse exemplo, a taxa de mortalidade infantil (TMI), está apresentado na última coluna da tabela. A média e a variância apresentadas não são parâmetros globais, simplesmente são parâmetros calculados para a distribuição das taxas dos municípios (Brasil. Ministério da Saúde, 2007). 
Métodos

\begin{tabular}{|l|c|c|c|c|c|c|}
\hline MUNicipıo & $\begin{array}{c}\text { Água } \\
\text { Santa }\end{array}$ & Bebedouro Cacimba & Nascente & Poço & TMI \\
\hline Água Santa & 0 & 1 & 0 & 1 & 1 & 22,3 \\
\hline Bebedouro & 1 & 0 & 0 & 1 & 0 & 26,5 \\
\hline Cacimba & 0 & 0 & 0 & 0 & 1 & 18,4 \\
\hline Nascente & 1 & 1 & 0 & 0 & 0 & 23,0 \\
\hline Poço & 1 & 0 & 1 & 0 & 0 & 20,7 \\
\hline Média das Taxas $(\bar{y})$ & & & & & 22,18 \\
\hline Variância das Taxas & & & & & 7,17 \\
\hline
\end{tabular}

FONTE: Brasil. Ministério da Saúde, 2007, p.68.

Figura 8 - Matriz de vizinhança espacial por adjacência e Taxas de Mortalidade Infantil (/1000 Nascidos Vivos)

A função de correlação usual compara valores de duas variáveis. A função de autocorrelação é a correlação do valor do indicador comparado aos valores do mesmo indicador nos municípios vizinhos e, matematicamente, é calculada da seguinte forma:

$$
1=\frac{1}{\sum_{i=1}^{n} \sum_{j=1}^{n} w_{i}} \times \frac{\sum_{i=1}^{n} \sum_{j=1}^{n} w_{i j}\left(y_{i}-\bar{y}\right)\left(y_{j}-\bar{y}\right)}{\operatorname{VAR}(y)}
$$

sendo $w_{i j}$ o indicador de vizinhança (no nosso exemplo 0 ou 1), $y_{i} \circ$ valor do indicador na área ie $y_{j}$ o valor em $j, \bar{y}$ a média e VAR $(y)$ a variância das taxas. 
Assim temos no numerador que, sempre que $i$ e $j$ forem vizinhas (1 na matriz acima), somamos o produto do desvio das áreas $i$ e $j$ em relação ao valor médio $\bar{y}$. No denominador temos simplesmente a variância do indicador (Brasil. Ministério da Saúde, 2007).

O valor da função de autocorrelação, para vizinhos diretos, é denominado estatística I de Moran, e utilizado como teste para verificar a presença de cluster espacial, determinando se áreas próximas são mais similares do que seria esperado por uma distribuição aleatória.

Foram considerados estatisticamente significantes os índices de Moran global que apresentaram $p<0,05$.

\section{b) Diagrama de Espalhamento de Moran}

Uma forma adicional de visualizar o índice global de Moran é através do diagrama de espalhamento de Moran (Figura 9), que permite visualizar espacialmente o relacionamento entre os valores do vetor de desvio e os valores das medias locais, indicando diferentes regimes espaciais presentes nos dados estudados. 


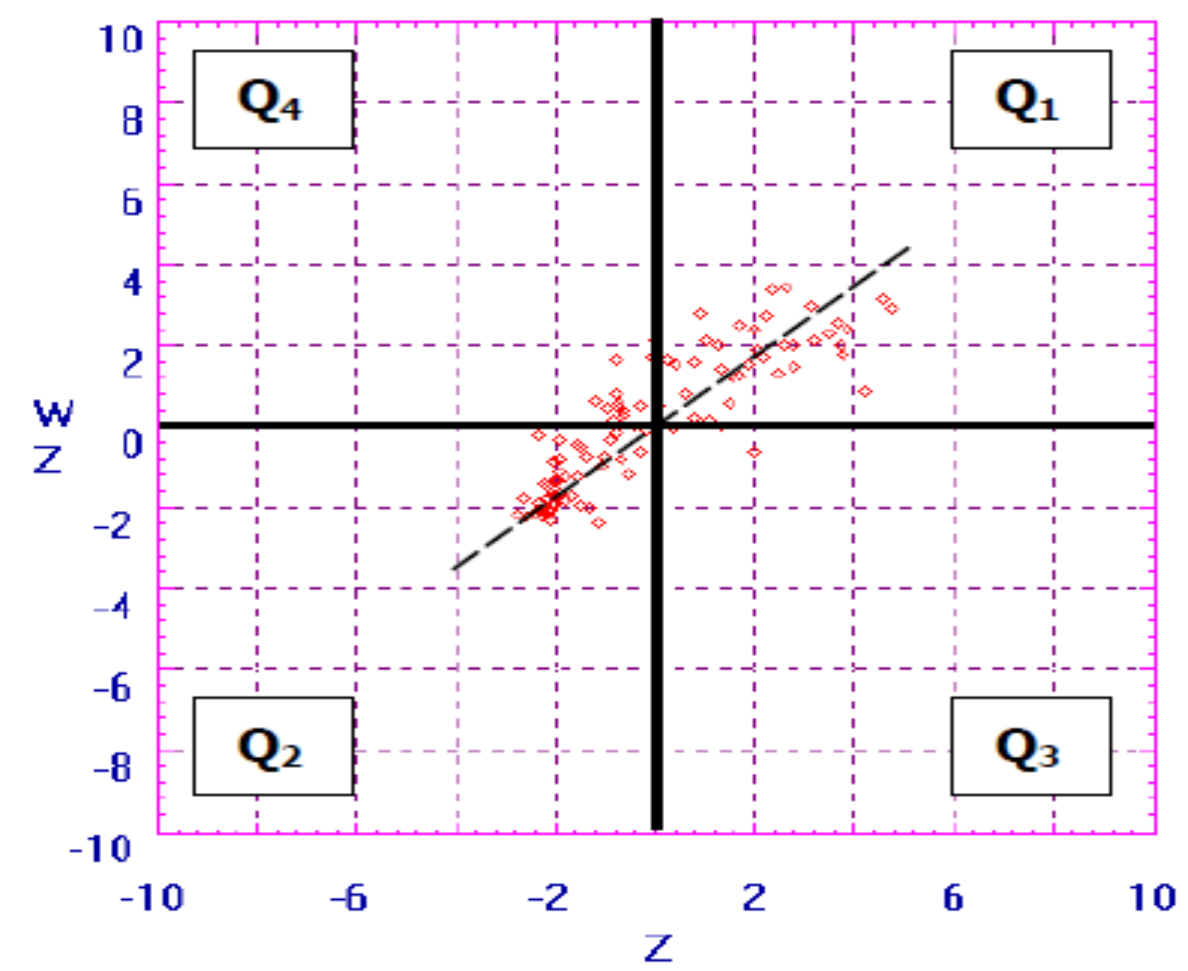

FONTE: Camargo, 2000, p.16.

Figura 9 - Diagrama de espalhamento de Moran

Os atributos utilizados para obtenção do diagrama de Moran são:

- no eixo X: Vetor dos desvios dos valores observados em relação a média;

- no eixo Y: Vetor da média ponderada local (valor da média dos vizinhos).

As áreas em estudo são classificadas em quatro grupos, apresentados em um gráfico de dispersão dividido em quadrantes (Q):

- Q1 (High high, HH ): alto-alto, valores positivos e médias positivas. Indicam pontos de associação espacial positiva, no sentido que uma localização possui altos valores do evento estudado e possui vizinhos com valores semelhantes e neste caso indica alta prioridade para intervenção;

- Q2 (Low low, LL): baixo-baixo, valores negativos e médias negativas; associação espacial positiva e baixa prioridade; 
- Q3 (HL): alto-baixo, valores positivos e médias negativas;

- Q4 (LH): baixo-alto, valores negativos e médias positivas.

Os pontos localizados em Q3(HL) e Q4(LH) possuem autocorrelação inversa ou negativa e indicam regiões que não seguem o mesmo processo de dependência espacial das demais observações. Estes pontos marcam regiões de transição entre regimes espaciais distintos (localização possui vizinhos com valores distintos).

O Diagrama de Espalhamento de Moran pode ser representado em forma de mapa, denominado box map, no qual cada polígono (área) é apresentado indicando-se seu quadrante no diagrama de espalhamento. Conforme exemplo na Figura 10, os municípios são agrupados em três grupos:

- Q1 - Alta prioridade;

- Q2 - Baixa prioridade;

- Q3 e Q4 - Média prioridade. 


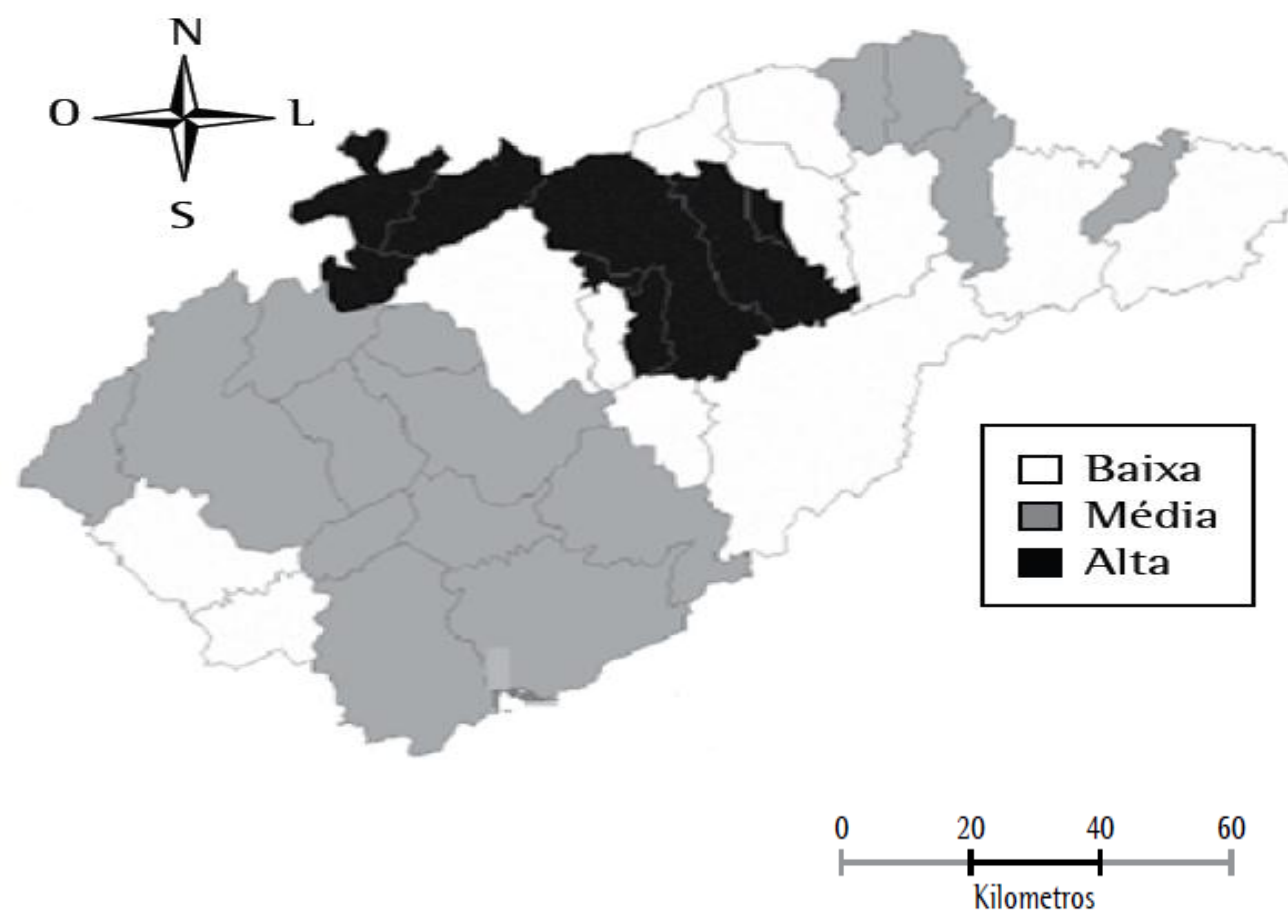

FONTE: Mukai et al., 2009.

Figura 10 - Distribuição dos municípios do Vale do Paraíba (SP), segundo prioridade de intervenção, segundo o número de internações por pneumonia em menores de um ano de idade

Este estudo foi aprovado pelo Comitê de Ética em Pesquisa da Universidade de Taubaté (UNITAU) e pela Comissão de Ética para Análise de Projetos de Pesquisa (CAPPesq) do Hospital das Clínicas da FMUSP ( ${ }^{\circ}$ 0053/09). 
4. RESULTADOS 


\section{RESULTADOS}

No período estudado foram incluídos 141.293 nascidos vivos (variação 150 - 44.624). Foram 2244 óbitos perinatais (variação 1 - 570), sendo 1123 (50\%) óbitos fetais e 1121 óbitos no período neonatal precoce.

A Tabela 1 mostra a descrição dos óbitos e do coeficiente de mortalidade perinatal nos municípios. Na Tabela 2 estão demonstrados os coeficientes de mortalidade fetal, neonatal precoce e perinatal. 
Resultados

Tabela 1 - Mortalidade perinatal no Vale do Paraíba, São Paulo - Brasil (2004-2008)

\begin{tabular}{|c|c|c|c|c|c|}
\hline Município & $\begin{array}{c}\text { Nascidos } \\
\text { Vivos }\end{array}$ & $\begin{array}{l}\text { Óbitos } \\
\text { fetais }\end{array}$ & $\begin{array}{l}\text { Óbitos } \\
\text { neonatais }\end{array}$ & $\begin{array}{l}\text { Óbitos } \\
\text { perinatais }\end{array}$ & $\begin{array}{l}\text { Coef. Mort. } \\
\text { perinatal \# }\end{array}$ \\
\hline Aparecida & 2481 & 27 & 25 & 52 & 20,9 \\
\hline Arapeí & 150 & 0 & 1 & 1 & 6,6 \\
\hline Areias & 277 & 2 & 5 & 7 & 25,3 \\
\hline Bananal & 792 & 3 & 12 & 15 & 18,9 \\
\hline Caçapava & 6111 & 55 & 50 & 105 & 17,2 \\
\hline Cachoeira Paulista & 2155 & 14 & 16 & 30 & 13,9 \\
\hline Campos do Jordão & 4341 & 60 & 49 & 109 & 25,1 \\
\hline Canas & 326 & 4 & 2 & 6 & 18,4 \\
\hline Cruzeiro & 5705 & 58 & 82 & 140 & 24,5 \\
\hline Cunha & 1459 & 22 & 17 & 39 & 26,7 \\
\hline Guaratinguetá & 7862 & 53 & 47 & 100 & 12,7 \\
\hline Igaratá & 704 & 6 & 11 & 17 & 24,1 \\
\hline Jacareí & 15759 & 112 & 112 & 224 & 14,2 \\
\hline Jambeiro & 269 & 4 & 7 & 11 & 40,9 \\
\hline Lagoinha & 266 & 3 & 1 & 4 & 15,0 \\
\hline Lavrinhas & 561 & 7 & 10 & 17 & 30,3 \\
\hline Lorena & 6277 & 66 & 49 & 115 & 18,3 \\
\hline Monteiro Lobato & 213 & 2 & 2 & 4 & 18,8 \\
\hline Natividade da Serra & 357 & 0 & 4 & 4 & 11,2 \\
\hline Paraibuna & 1107 & 4 & 11 & 15 & 13,5 \\
\hline Pindamonhangaba & 10520 & 90 & 84 & 174 & 16,5 \\
\hline Piquete & 909 & 13 & 11 & 24 & 26,4 \\
\hline Potim & 1235 & 11 & 18 & 29 & 23,5 \\
\hline Queluz & 804 & 12 & 9 & 21 & 26,1 \\
\hline Redencao da Serra & 253 & 3 & 2 & 5 & 19,8 \\
\hline Roseira & 674 & 8 & 9 & 17 & 25,2 \\
\hline Santa Branca & 907 & 8 & 5 & 13 & 14,3 \\
\hline $\begin{array}{l}\text { Santo Antonio do } \\
\text { Pinhal }\end{array}$ & 483 & 11 & 5 & 16 & 33,1 \\
\hline São Bento do Sapucaí & 617 & 6 & 5 & 11 & 17,8 \\
\hline São Jose do Barreiro & 282 & 2 & 5 & 7 & 24,8 \\
\hline São Jose dos Campos & 44624 & 268 & 302 & 570 & 12,8 \\
\hline São Luis do Paraitinga & 660 & 5 & 6 & 11 & 16,7 \\
\hline Silveiras & 387 & 7 & 3 & 10 & 25,8 \\
\hline Taubaté & 19316 & 142 & 129 & 271 & 14,0 \\
\hline Tremembé & 2450 & 30 & 20 & 50 & 20,4 \\
\hline
\end{tabular}

\#Coeficiente de mortalidade perinatal=óbitos fetais + óbitos neonatais precoces/1000 nascidos vivos+óbitos fetais 
O maior coeficiente de mortalidade perinatal foi observado na cidade de Jambeiro (40,9/1000 nascimentos) e o menor na cidade de Arapeí (6,6/1000 nascimentos).

Tabela 2 - Coeficientes de mortalidade fetal, neonatal precoce e perinatal, por 1000 nascimentos, no Vale do Paraíba, São Paulo - Brasil (2004-2008)

\begin{tabular}{lllc}
\hline $\begin{array}{l}\text { Coeficiente de } \\
\text { Mortalidade }\end{array}$ & Média (DP) & Variação & Mediana \\
\hline Fetal & $10,3(4,4)$ & $3,7-26,0$ & 9,1 \\
Neonatal Precoce & $10,1(4,7)$ & $0,0-22,7$ & 9,7 \\
Perinatal & $20,4(6,8)$ & $6,6-40,8$ & 18,9
\end{tabular}

As Figuras 11, 12 e 13 mostram a distribuição dos coeficientes de mortalidade fetal, neonatal precoce e perinatal por 1000 nascimentos, por agrupamento em quartis. 


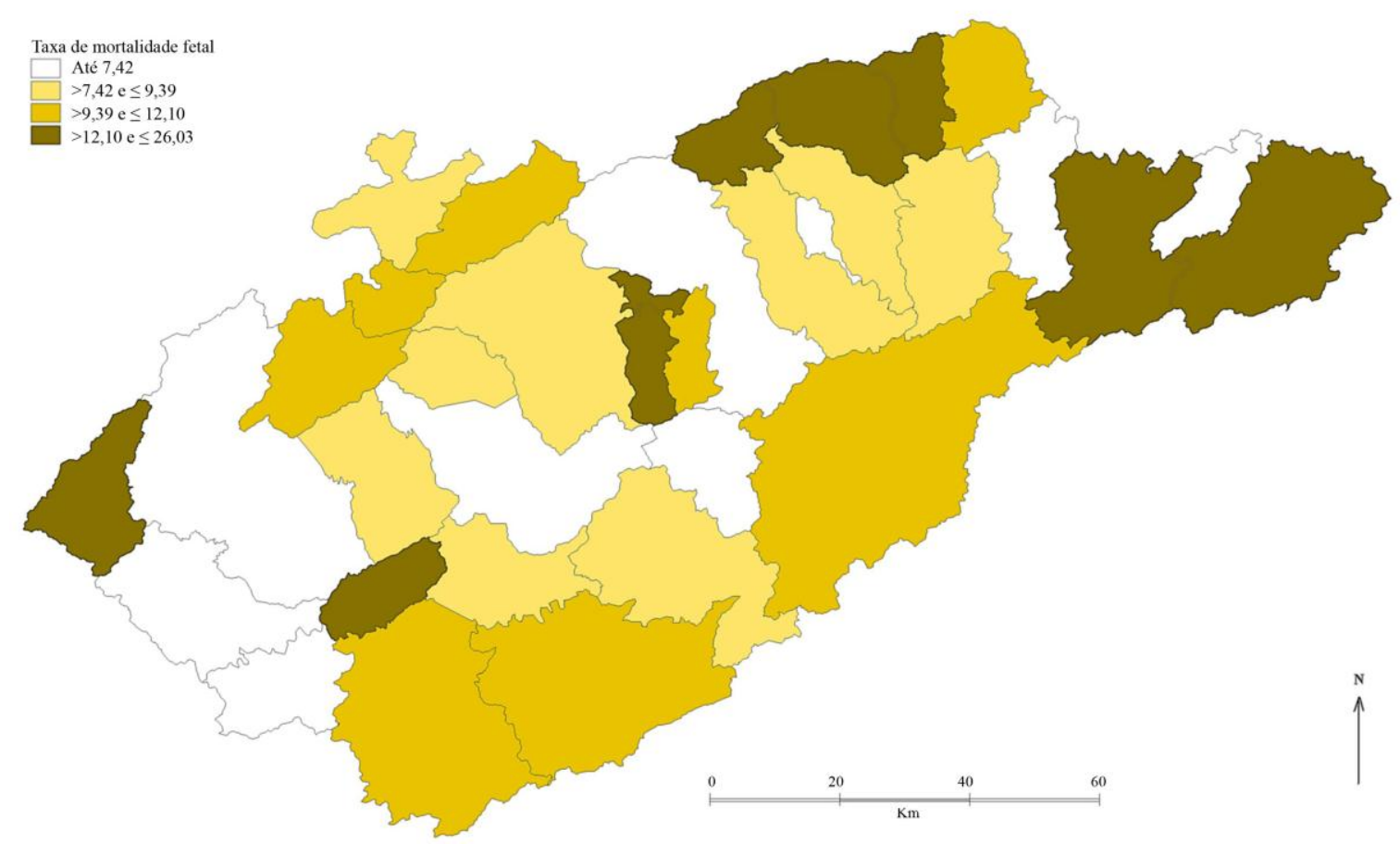

Figura 11 - Distribuição espacial do coeficiente de mortalidade fetal, por 1000 nascimentos, no Vale do Paraíba (SP), 2004-2008

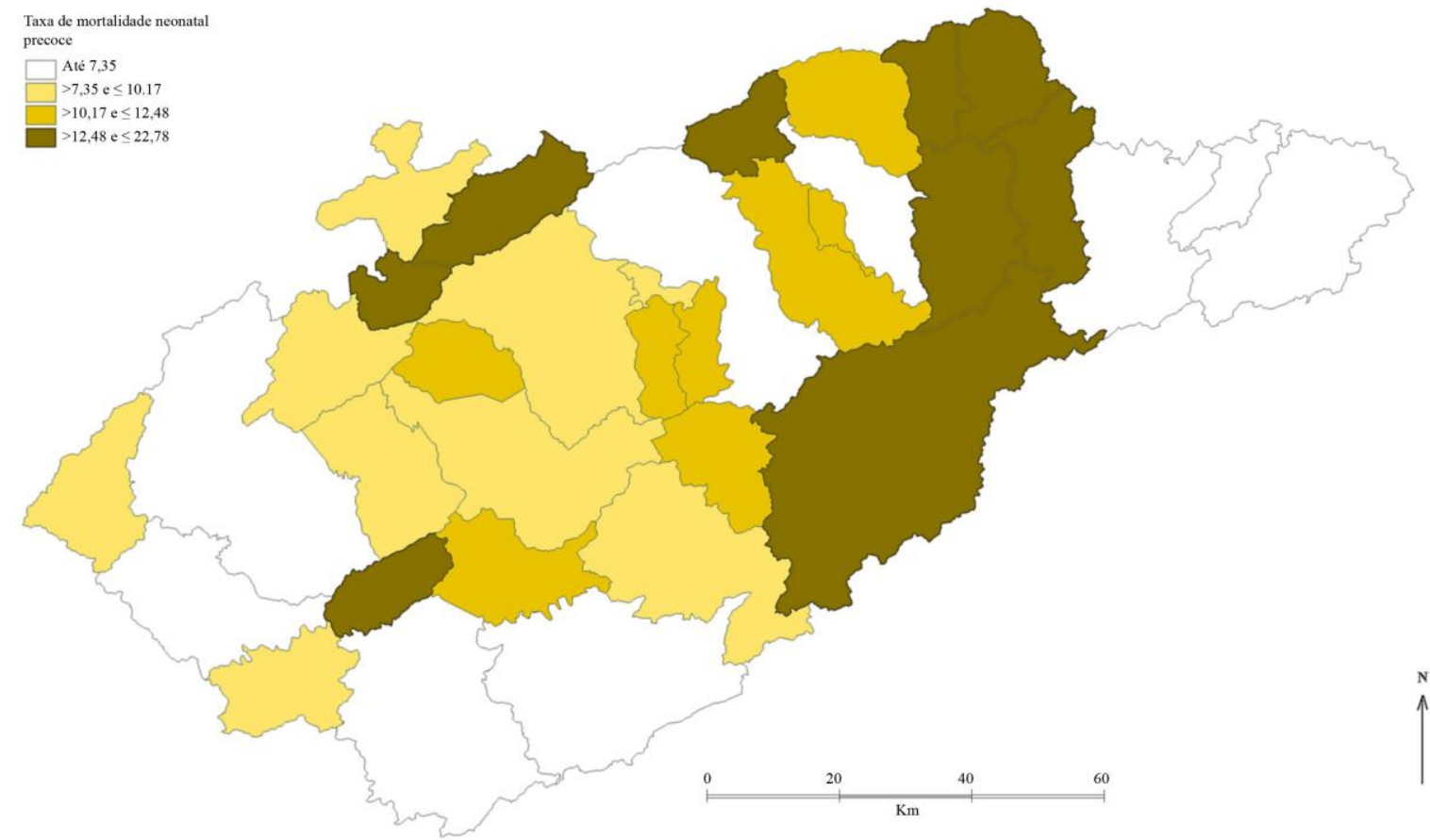

Figura 12 - Distribuição espacial do coeficiente de mortalidade neonatal precoce, por 1000 NV, no Vale do Paraíba (SP), 2004-2008 


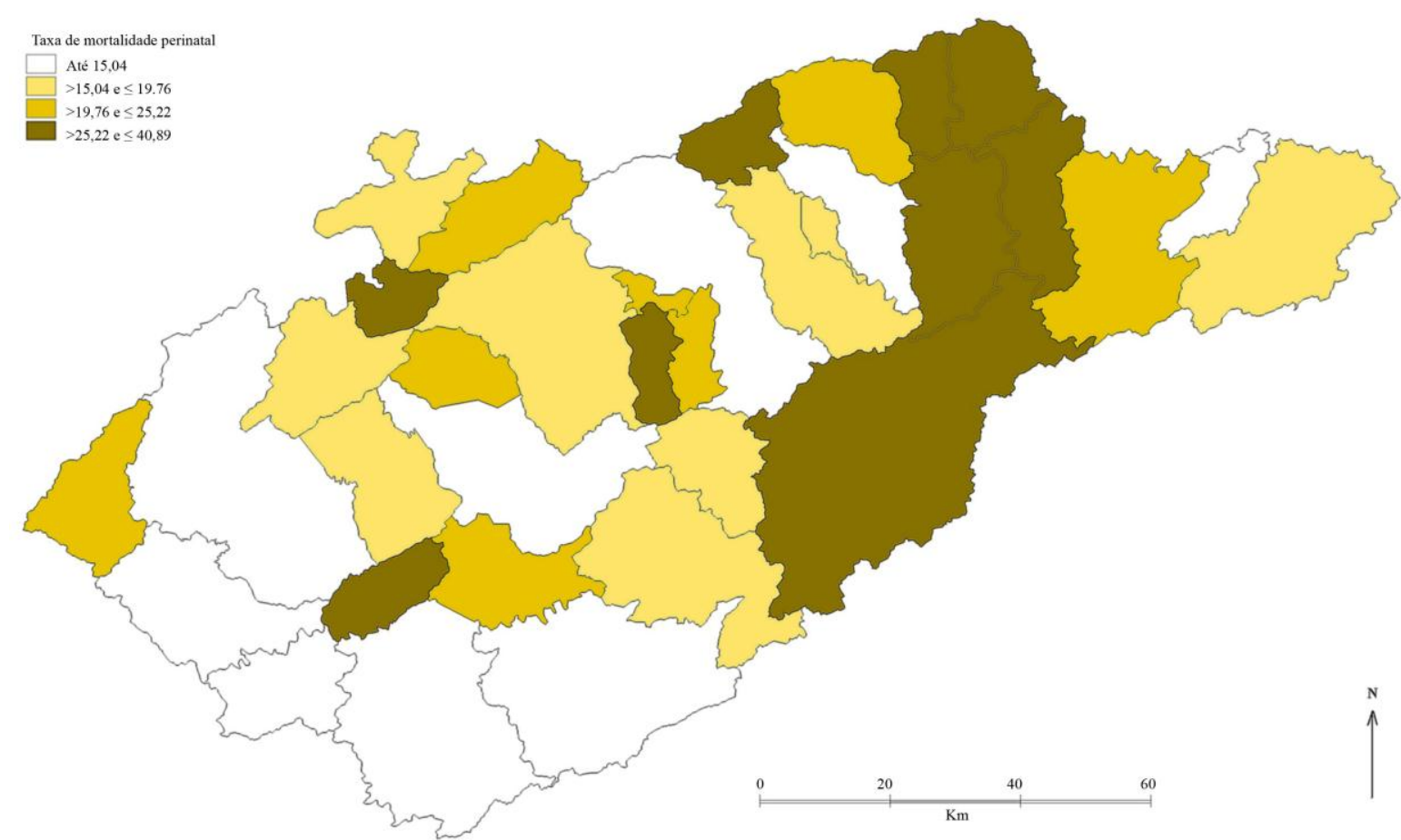

Figura 13 - Distribuição espacial da coeficiente de mortalidade perinatal, por 1000 nascimentos, no Vale do Paraíba (SP), 2004-2008

Podemos observar na Figura 11 que a distribuição espacial nos quartis apresentados nos mapas mostrou valores mais elevados (quartil de 12,1 a 26,0) de coeficiente de mortalidade fetal nos municípios de Jambeiro e Igaratá, Roseira, Potim, Lavrinhas, Cruzeiro, Piquete, Bananal e São José do Barreiro e que nos municípios de Jacareí, Santa Branca, São José dos Campos, Taubaté, Lagoinha, Guaratinguetá, Canas, Areias e Arapeí foram encontrados os menores valores $(3,75$ a 7,42$)$.

Quanto ao coeficiente de mortalidade neonatal precoce podemos observar na Figura 12 que os valores mais elevados (12,48 a 22,78) foram encontrados em cidades da porção oriental Vale do Paraíba (Piquete, Lavrinhas, Queluz, Areias, Silveiras e Cunha), na Serra da Mantiqueira (Campos do Jordão e Santo Antonio do Pinhal) e isoladamente na cidade de 
Resultados

Jambeiro. Valores mais baixos (zero a 7,35 ) foram observados nos municípios do Vale do Paraíba histórico (Arapeí, Bananal e São José do Barreiro), Natividade da Serra, Paraibuna, Cachoeira Paulista, Guaratinguetá, Jacareí e São José dos Campos.

$\mathrm{Na}$ distribuição espacial do coeficiente de mortalidade perinatal, observamos valores mais baixos $(6,6$ a 15,0$)$ novamente nas cidades de Jacareí, Santa Branca, São José dos Campos, Taubaté, Guaratinguetá e Arapeí e também em Natividade da Serra, Paraibuna e Cachoeira Paulista. E os mais elevados $(25,2$ a 40,9) em um aglomerado incluindo as cidades de Queluz, Lavrinhas, Areias, Silveiras e Cunha mais as cidades de Piquete, Roseira, Santo Antonio do Pinhal e Jambeiro.

Na Tabela 3 encontram-se os valores do índice de Moran global para os coeficientes de mortalidade fetal, neonatal precoce e perinatal.

Tabela 3 - Índices de Moran dos coeficientes de mortalidade fetal, neonatal precoce e perinatal por 1000 nascimentos, no Vale do Paraíba (SP), 2004-2008

\begin{tabular}{lcl}
\hline $\begin{array}{l}\text { Coeficiente de } \\
\text { Mortalidade }\end{array}$ & $\begin{array}{c}\text { Índice de } \\
\text { Moran }\end{array}$ & $\mathbf{p}$ \\
\hline Fetal & $-0,14$ & 0,10 \\
Neonatal Precoce & 0,24 & 0,03 \\
Perinatal & $-0,05$ & 0,37
\end{tabular}


O índice de Moran global para o coeficiente de mortalidade neonatal precoce foi o único com significância estatística $(p=0,03)$, conforme Tabela 3.

Estes valores indicam dependência espacial entre os municípios analisados quanto à mortalidade neonatal precoce, sendo que para a mortalidade fetal e perinatal não houve significância estatística, apesar do mapa de distribuição espacial do coeficiente de mortalidade perinatal ter identificado um aglomerado de municípios com coeficientes mais elevados.

$\mathrm{Na}$ Tabela 4 encontram-se os valores do índice de Moran global para as variáveis estudadas em relação ao óbito fetal, por 1000 nascimentos.

Tabela 4 - Índices de Moran dos coeficientes de mortalidade fetal e variáveis estudadas por 1000 nascimentos, no Vale do Paraíba (SP), 2004-2008

\begin{tabular}{lcc}
\hline \multicolumn{1}{c}{ Variável } & Índice de Moran & p-valor \\
\hline Adolescente (10 e 19 anos) & $-0,24$ & 0,02 \\
Adulta (a partir 20 anos) & $-0,08$ & 0,22 \\
Escolaridade baixa & $-0,02$ & 0,42 \\
Escolaridade alta & $-0,12$ & 0,14 \\
Sexo masculino & 0,18 & 0,07 \\
Peso até 1499g & $-0,15$ & 0,11 \\
Peso até 2499g & $-0,11$ & 0,14 \\
Peso de 2500 a 3999g & $-0,15$ & 0,07
\end{tabular}

Nas variáveis estudadas, podemos observar uma contribuição maior da variável gestante adolescente na mortalidade fetal. Na Figura 14 encontra-se 
o mapa com a distribuição da taxa de mortalidade fetal com a representação das taxas de idade da gestante.

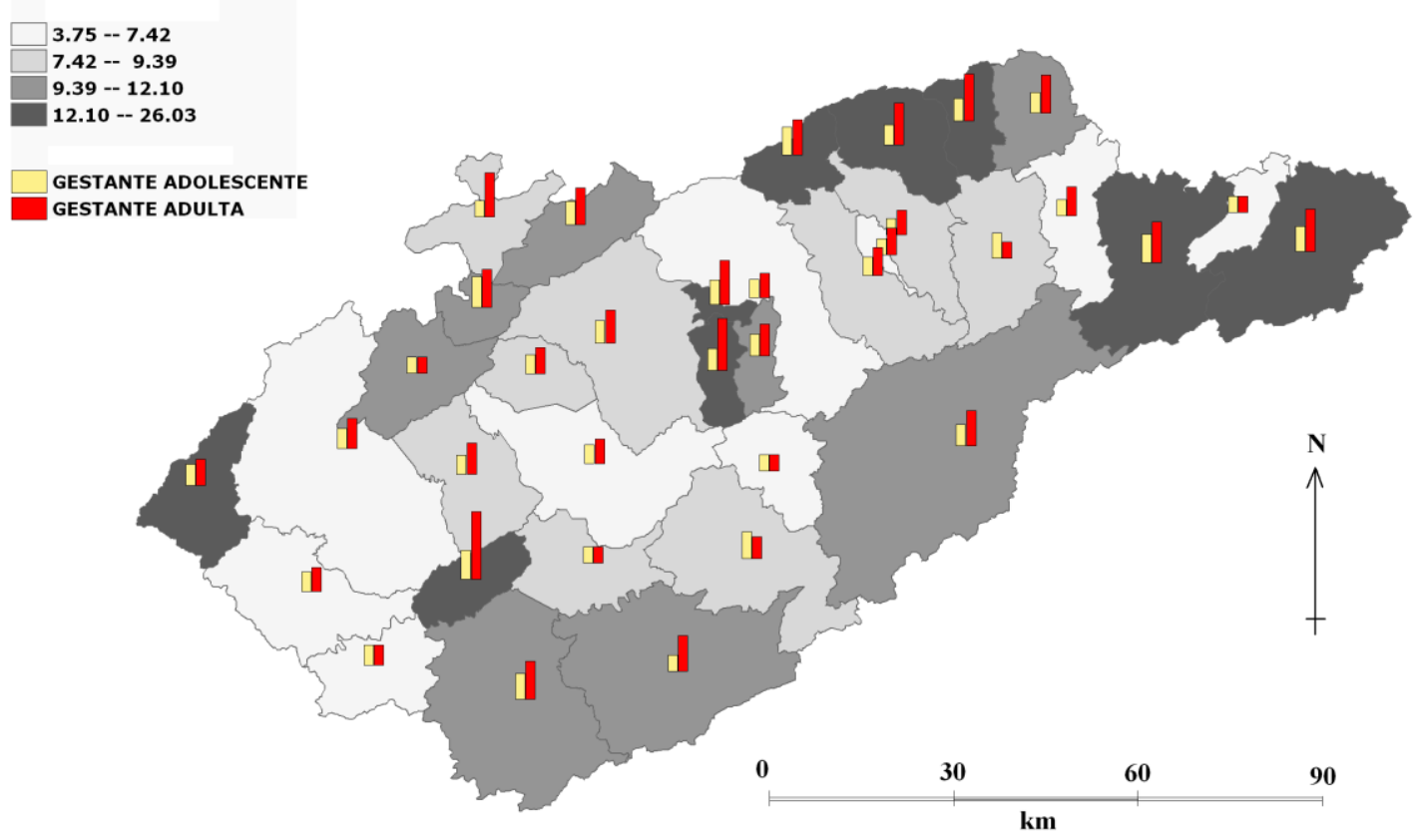

Figura 14 - Distribuição espacial do coeficiente de mortalidade fetal com representação em gráfico de barras para idade da gestante, por 1000 nascimentos, no Vale do Paraíba (SP), 2004-2008

Na Tabela 5 encontram-se os valores do índice de Moran global para as variáveis estudadas em relação ao óbito neonatal precoce, por 1000 nascidos vivos. 
Resultados

Tabela 5 - Índices de Moran dos coeficientes de mortalidade neonatal precoce e variáveis estudadas, por 1000 NV, no Vale do Paraíba (SP), 2004-2008

\begin{tabular}{lcc}
\hline \multicolumn{1}{c}{ Variável } & Índice de Moran & p-valor \\
\hline Adolescente (10 e 19 anos) & $-0,05$ & 0,37 \\
Adulta (a partir 20 anos) & 0,39 & 0,01 \\
Escolaridade baixa & 0,38 & 0,01 \\
Escolaridade alta & 0,22 & 0,05 \\
Peso até 999g & $-0,01$ & 0,42 \\
Peso até 1499g & 0,09 & 0,29 \\
Peso até 2499g & 0,15 & 0,11 \\
Peso de 2500 a 3999g & $-0,15$ & 0,07 \\
Peso $\geq 4000 g$ & $-0,03$ & 0,45 \\
Parto vaginal & 0,23 & 0,04 \\
Parto cesáreo & 0,11 & 0,18 \\
Sexo masculino & 0,15 & 0,05 \\
IG de 22 a 27 semanas & 0,08 & 0,25 \\
IG de 28 a 31 semanas & $-0,05$ & 0,32 \\
IG de 32 a 36 semanas & 0,32 & 0,02 \\
\hline
\end{tabular}

Nas variáveis estudadas, observamos uma contribuição maior das variáveis gestante adulta, escolaridade baixa, parto vaginal e gestação de 32 a 36 semanas na mortalidade neonatal precoce. As representações da distribuição espacial do coeficiente de mortalidade neonatal precoce com as taxas das variáveis estudadas, expressas em gráficos de barras, estão nas Figuras 15 a 18. 
Taxa de mortalidade neonatal

precoce

Até 7,35

$>7,35$ e $\leq 10,17$

$>10,17 \mathrm{e} \leq 12,48$

$>12,48$ e $\leq 22,78$

Idade materna

Taxa gestante adulta

Taxa gestante adolescente

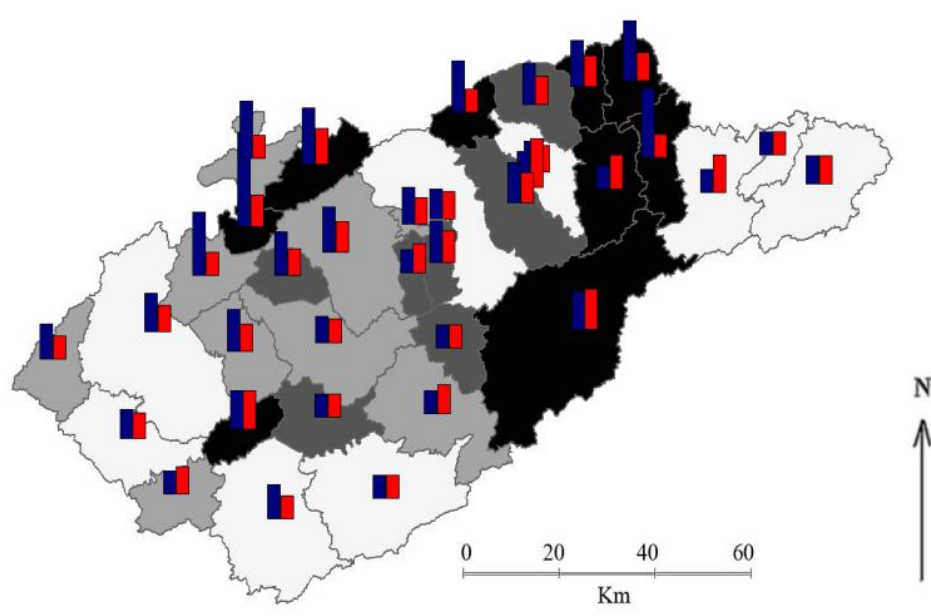

Figura 15 - Distribuição espacial do coeficiente de mortalidade neonatal precoce com representação em gráfico de barras para idade materna, por 1000 NV, no Vale do Paraíba (SP), 2004-2008
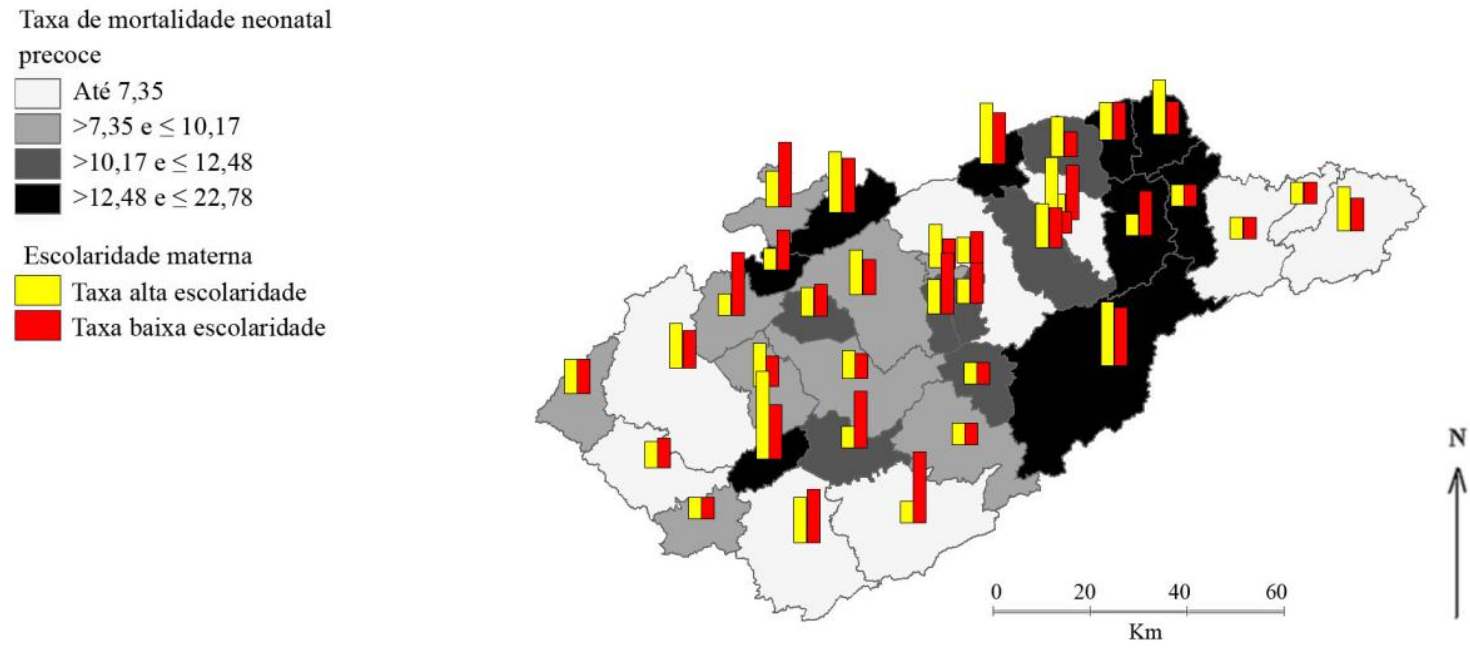

Figura 16 - Distribuição espacial do coeficiente de mortalidade neonatal precoce com representação em gráfico de barras para tipo de parto, por 1000 NV, no Vale do Paraíba (SP), 2004-2008 


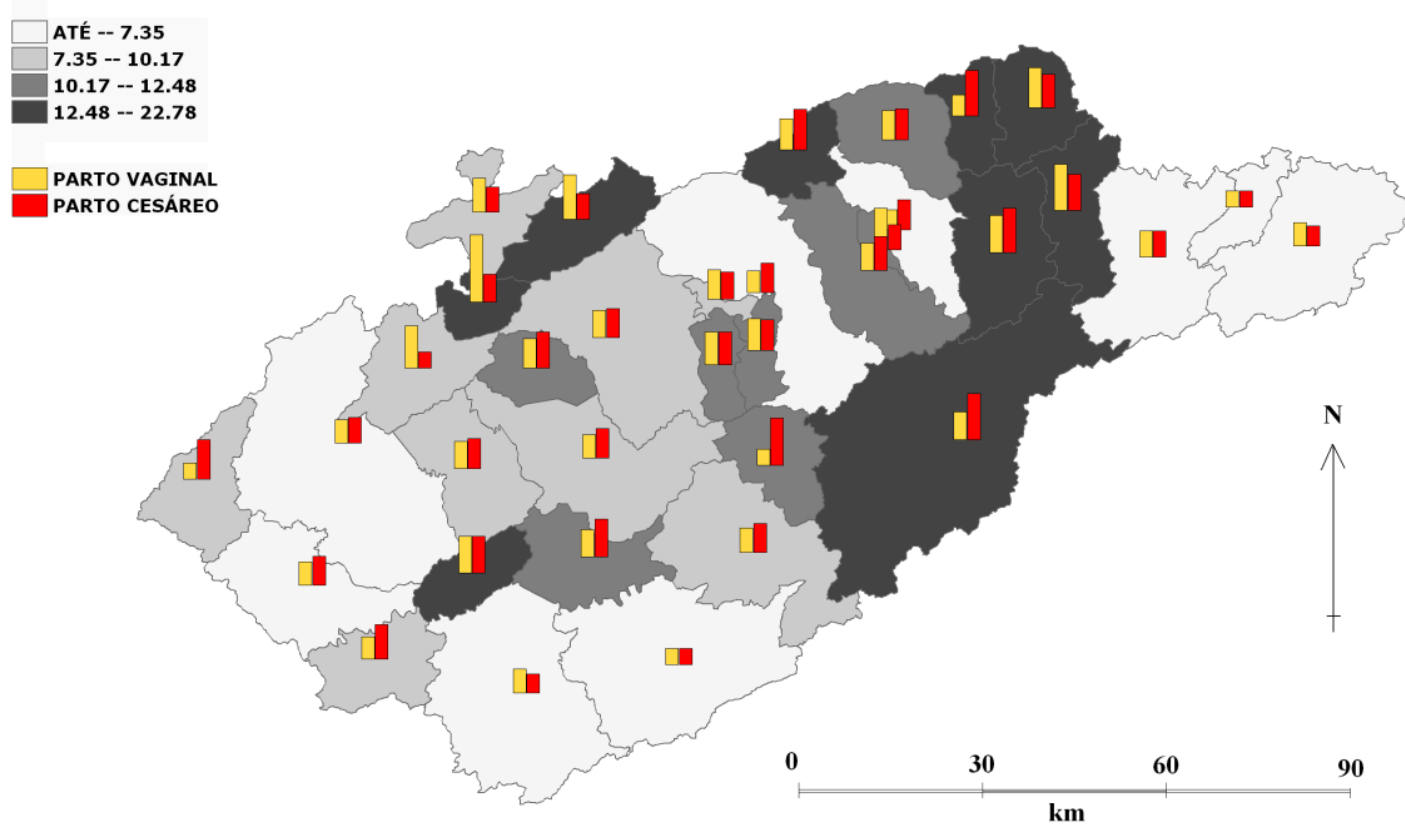

Figura 17 - Distribuição espacial do coeficiente de mortalidade neonatal precoce com representação em gráfico de barras para escolaridade materna, por $1000 \mathrm{NV}$, no Vale do Paraíba (SP), 2004-2008

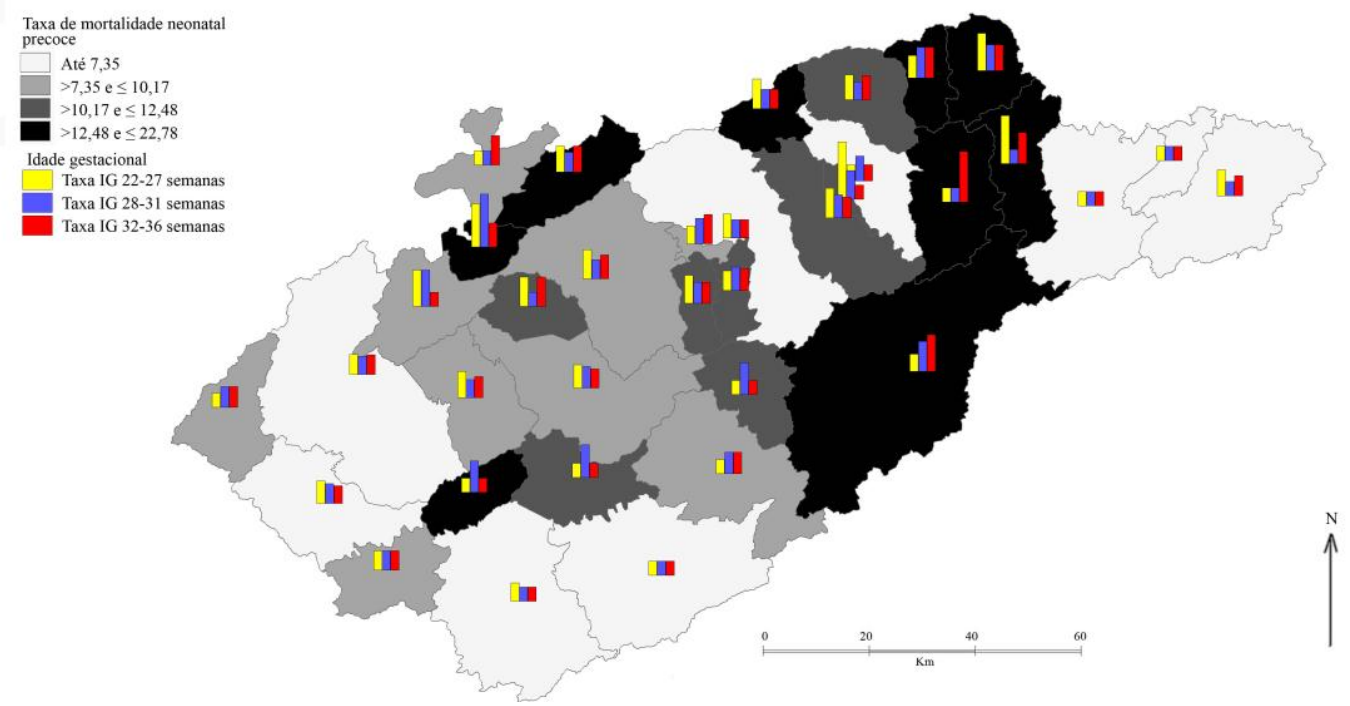

Figura 18 - Distribuição espacial do coeficiente de mortalidade neonatal precoce com representação em gráfico de barras para idade gestacional, por $1000 \mathrm{NV}$, no Vale do Paraíba (SP), 2004-2008 
$\mathrm{Na}$ Tabela 6 encontram-se os valores do índice de Moran global para as variáveis estudadas em relação ao óbito perinatal por 1000 nascimentos.

Tabela 6 - Índices de Moran do coeficiente de mortalidade perinatal e variáveis estudadas por 1000 nascimentos, no Vale do Paraíba (SP), 2004-2008

\begin{tabular}{lcc}
\hline \multicolumn{1}{c}{ Variável } & Índice de Moran & p-valor \\
\hline Adolescente (10 e 19 anos) & $-0,23$ & 0,03 \\
Adulta (a partir 20 anos) & 0,17 & 0,06 \\
Escolaridade baixa & 0,14 & 0,11 \\
Escolaridade alta & 0,11 & 0,17 \\
Peso do RN até 2499g & $-0,01$ & 0,39 \\
Sexo masculino & 0,07 & 0,24 \\
\hline
\end{tabular}

Nas variáveis estudadas, encontramos uma contribuição maior da variável gestante adolescente. A representação da distribuição espacial do coeficiente de mortalidade perinatal com a variável idade materna, está na Figura 19. 


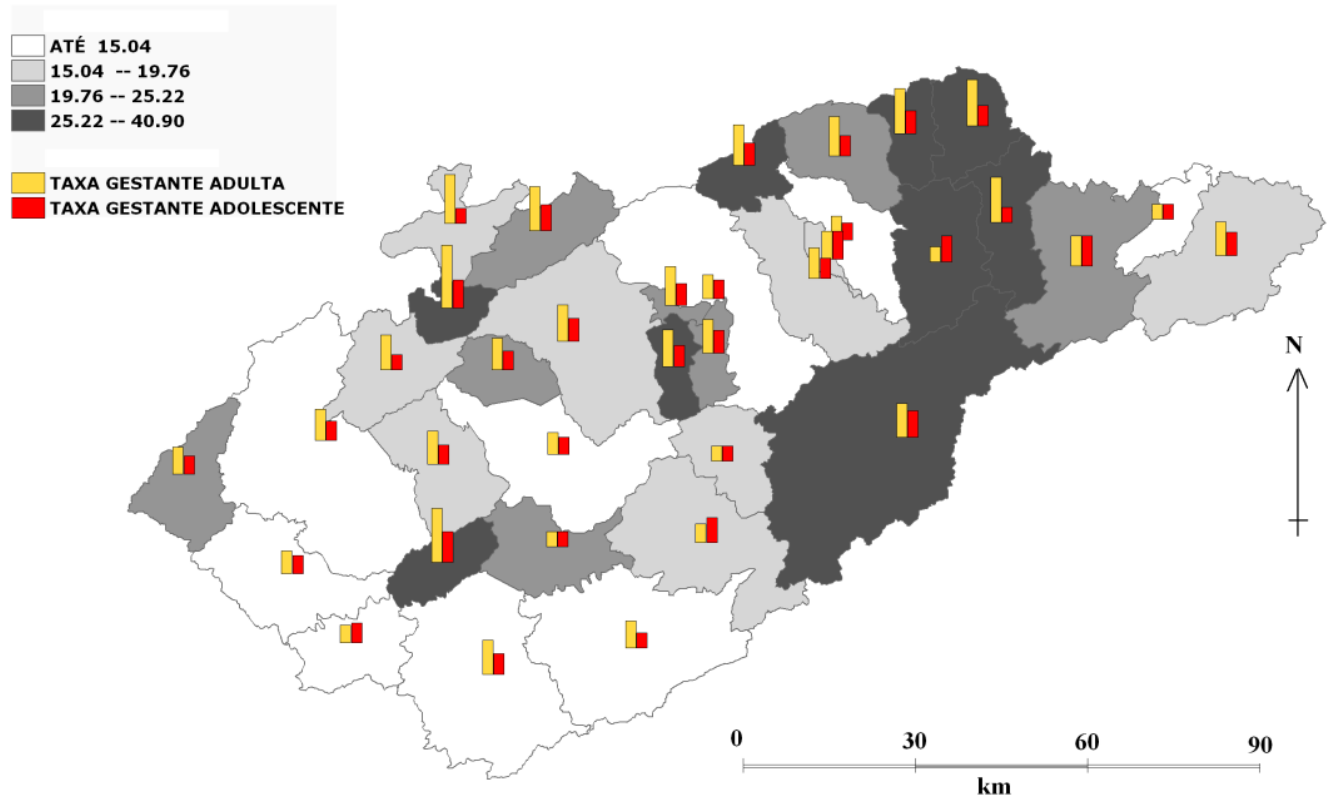

Figura 19 - Distribuição espacial do coeficiente de mortalidade perinatal com representação em gráfico de barras para idade materna, por 1000 nascimentos, no Vale do Paraíba (SP), 2004-2008

A distribuição espacial do Índice Paulista de Responsabilidade Social em agrupamento por valor único está ilustrada na Figura 20. Foi encontrada correlação entre os coeficientes de mortalidade neonatal precoce e perinatal com o IPRS, conforme sintetizado na Tabela 7. 


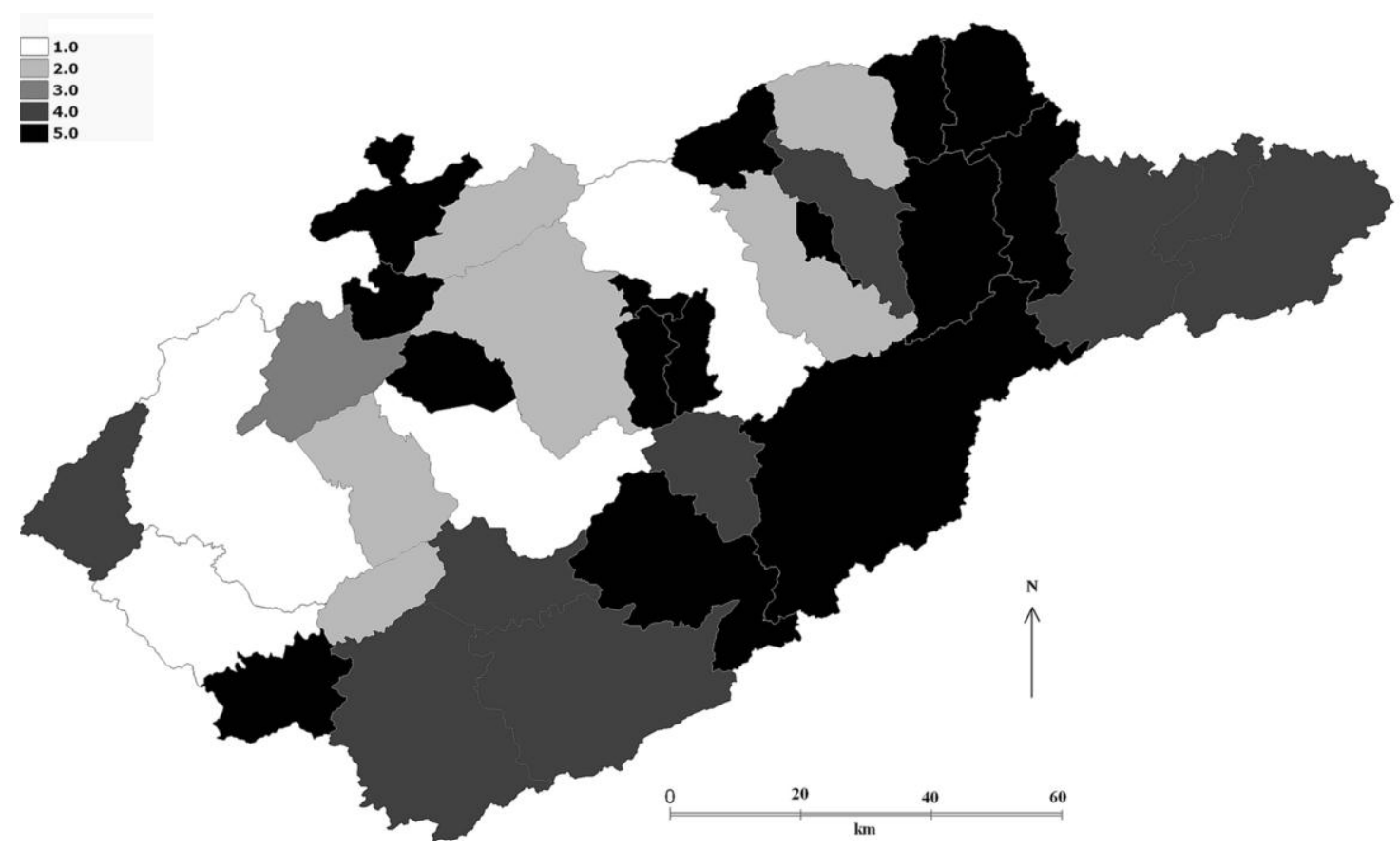

Figura 20 - Distribuição espacial do Índice Paulista de Responsabilidade Social (IPRS) no Vale do Paraíba (SP) no ano de 2006

Tabela 7 - Correlação entre coeficientes de mortalidade fetal, neonatal precoce e perinatal (2004-2008) e IPRS (2006) no Vale do Paraíba - SP

\begin{tabular}{lcc} 
Coeficiente de mortalidade & $\mathbf{r}_{\mathbf{s}}{ }^{*}$ & $\mathbf{p}$ \\
\hline Fetal & 0,18 & 0.28 \\
Neonatal precoce & 0,83 & $<0.0001$ \\
Perinatal & 0,47 & 0.004
\end{tabular}

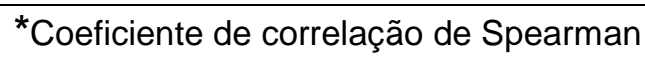


Foram identificados municípios com altos coeficientes de mortalidade perinatal, neonatal precoce e fetal, cercados por vizinhos com altos coeficientes, representando municípios com alta prioridade de intervenção, conforme observamos na representação em box map nas Figuras 21, 22 e 23.

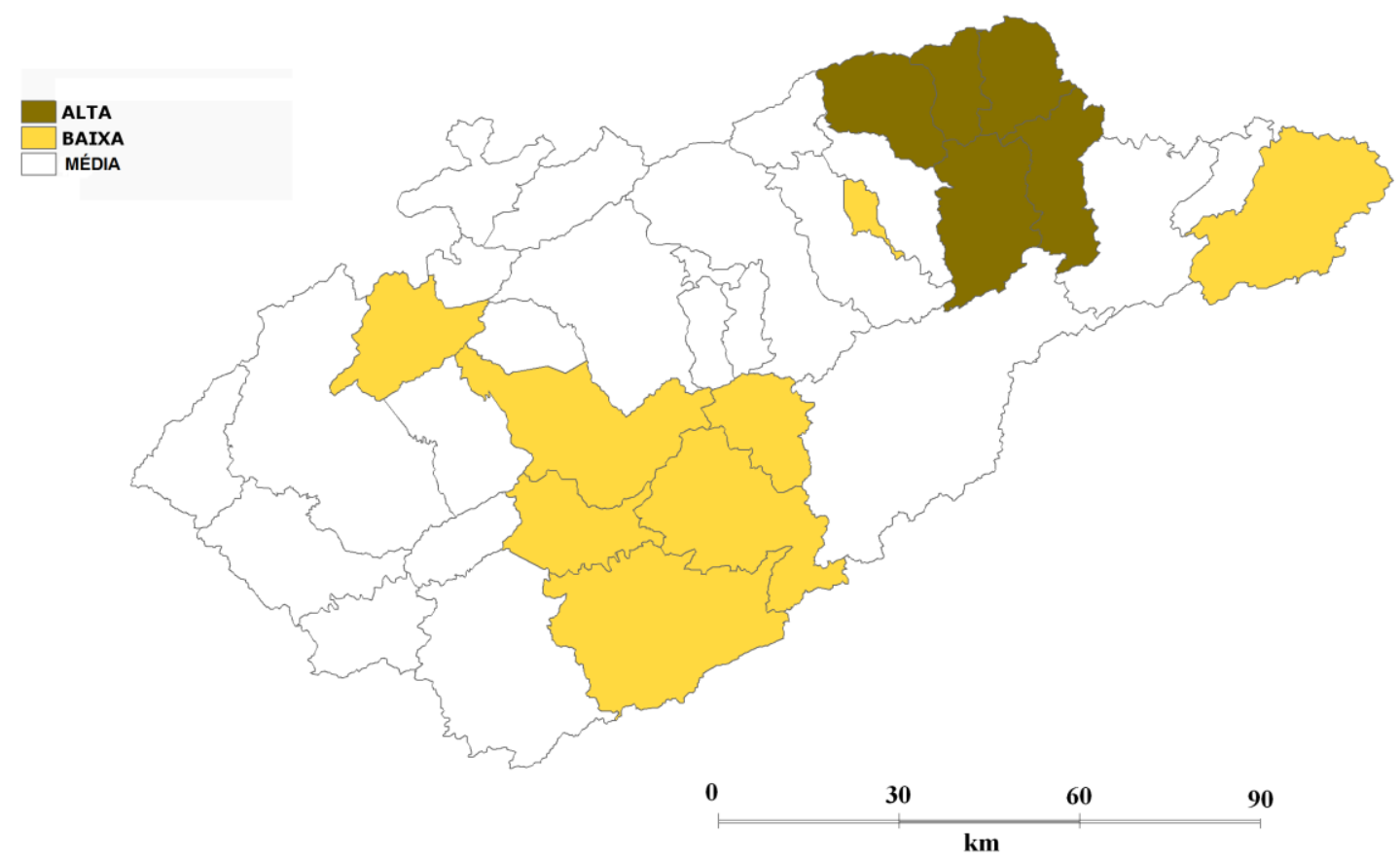

Figura 21 - Representação em box map do Diagrama de Espalhamento de Moran da mortalidade perinatal no Vale do Paraíba-SP (2004-2008) 


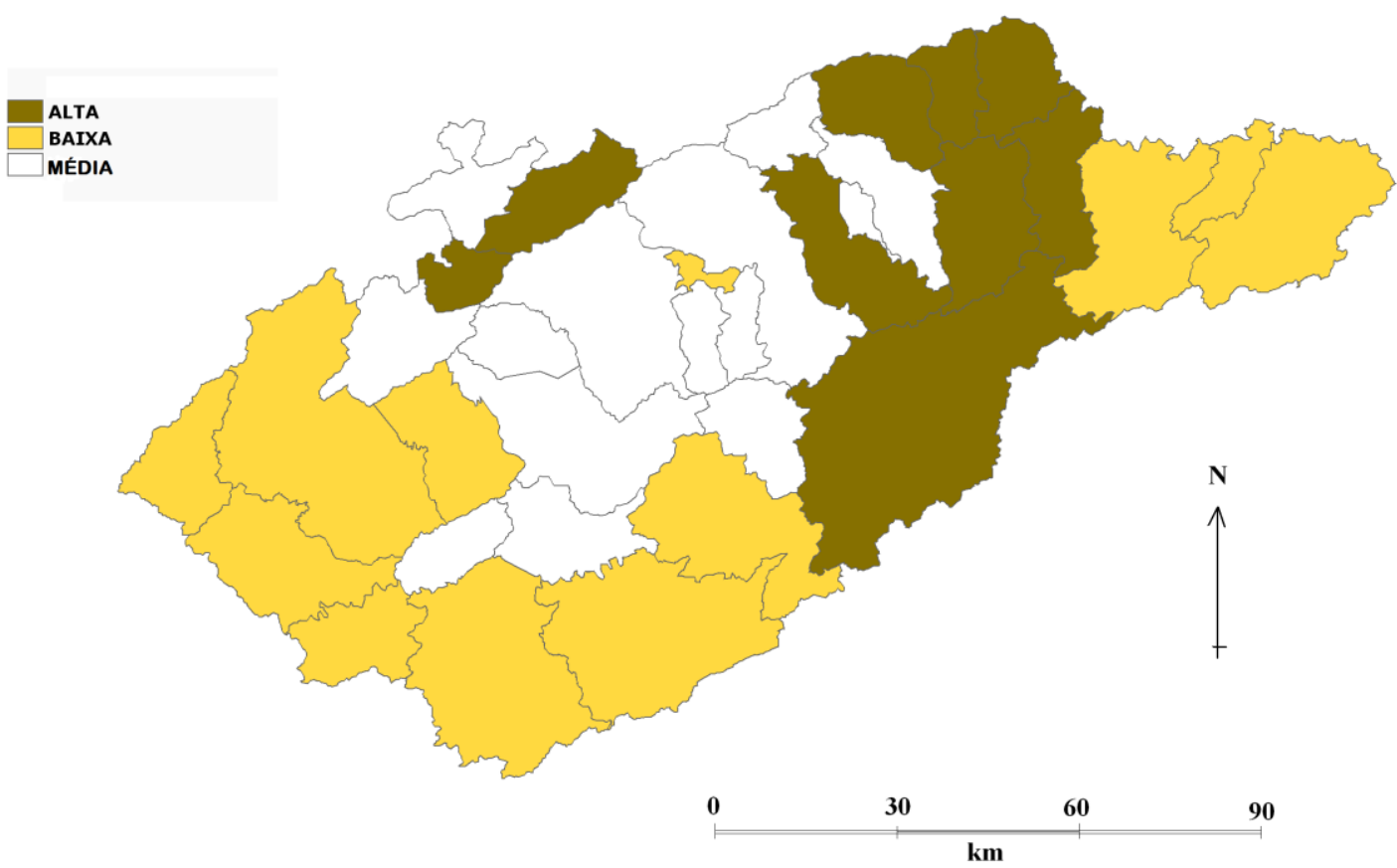

Figura 22 - Representação em box map do Diagrama de Espalhamento de Moran da mortalidade neonatal precoce no Vale do Paraíba-SP (2004-2008)

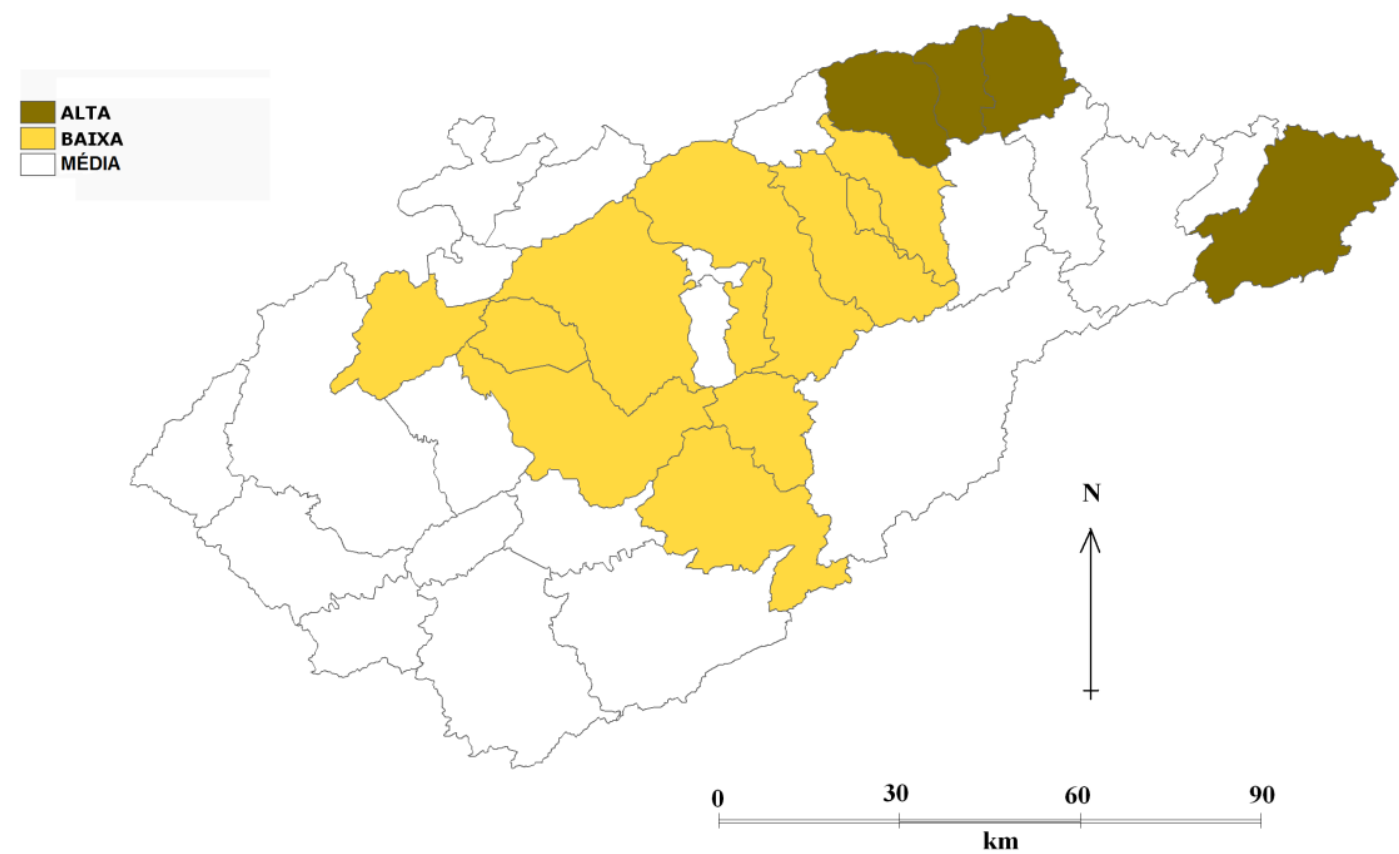

Figura 23 - Representação em box map do Diagrama de Espalhamento de Moran da mortalidade fetal no Vale do Paraíba-SP (2004-2008) 
5. DISCUSSÃO 


\section{DISCUSSÃO}

O presente trabalho representa o primeiro estudo analisando mortalidade perinatal com técnicas de análise espacial no Brasil com o objetivo de identificar aglomerados de municípios com elevados coeficientes de mortalidade na região do Vale do Paraíba.

No período estudado o número de óbitos perinatais foi de 2244 , sendo $50 \%$ de óbitos fetais e $50 \%$ de óbitos neonatais precoces. Os dados atuais relativos ao Brasil e ao Estado de São Paulo mostram leve predomínio de óbitos fetais na mortalidade perinatal (DATASUS, 2011b). Esse comportamento é observado na maioria das regiões do mundo, porém, nos países em desenvolvimento, os óbitos fetais ocorrem principalmente no período intraparto, por falta de assistência apropriada ao nascimento, enquanto nos países desenvolvidos ocorrem antes do início do trabalho de parto, em consequência de complicações da gravidez e de doenças maternas (Martins et al., 2010).

A distribuição espacial da mortalidade perinatal no Vale do Paraíba permitiu visualizar um aglomerado de maior risco, com coeficientes de 25,2 a 40,9/1000 nascimentos, que compreende os municípios de Queluz, Lavrinhas, Areias, Silveiras e Cunha, mais as cidades de Piquete e Roseira, que são próximas, mais os municípios de Santo Antonio do Pinhal e Jambeiro. Os coeficientes mais baixos (6,7 a 15,0/1000 nascimentos) foram encontrados nas cidades de Jacareí, Santa Branca, São José dos Campos, Taubaté, Guaratinguetá, Arapeí, Natividade da Serra, Paraibuna e Cachoeira 
Paulista. Portanto, a distribuição espacial do coeficiente de mortalidade perinatal permitiu identificar municípios com maiores coeficientes formando um aglomerado na porção centro-oriental do Vale do Paraíba e municípios com menores coeficientes principalmente às margens da Rodovia Presidente Dutra, em direção a São Paulo.

Nos municípios da região, a visualização dos coeficientes de mortalidade neonatal precoce e perinatal apresentou padrão semelhante de distribuição. Quando utilizada a análise espacial global foi demonstrada a existência de autocorrelação espacial entre os municípios da região analisada para o coeficiente de mortalidade neonatal precoce.

Com relação à mortalidade fetal observamos um padrão em mosaico não havendo autocorrelação espacial significante pelo índice de Moran. $\mathrm{O}$ componente fetal representou a metade do coeficiente da mortalidade perinatal e, possivelmente devido a esse comportamento, não foi encontrada significância para a mortalidade perinatal.

No Brasil, os primeiros estudos utilizando a distribuição espacial como ferramenta para estudar a mortalidade infantil surgiram no final da década de 1990. Leal \& Szwarcwald (1997), em análise da distribuição espacial da mortalidade neonatal nos municípios do Estado do Rio de Janeiro em dois períodos, 1979-1981 e 1990-1992, demonstraram no primeiro período a presença de aglomerados de municípios com taxas muito elevadas de mortalidade neonatal tardia, que se associavam diretamente a baixas condições de vida. D'Orsi \& Carvalho (1998) concluíram que a metodologia 
permitiu aprofundar o conhecimento sobre o perfil de nascimentos em diferentes bairros do Município do Rio de Janeiro, no ano de 1994.

Morais Neto et al. (2001) utilizaram essa técnica para análise da mortalidade infantil na cidade de Goiânia. Os autores estudaram a distribuição espacial dos componentes neonatal e pós-neonatal da mortalidade infantil e encontraram áreas de risco concentradas nas regiões periféricas do município para o componente pós-neonatal (Morais Neto et al., 2001).

Na região do Vale do Paraíba, Nascimento et al. (2007) estudaram o padrão de distribuição espacial da mortalidade neonatal nos anos de 1999 a 2001 e identificaram um aglomerado de municípios com altas taxas de mortalidade neonatal na porção centro-oriental do Vale do Paraíba, com padrão espacial semelhante ao da mortalidade neonatal precoce. Os coeficientes foram menores tanto na direção da divisa com o estado do Rio de Janeiro como em direção à cidade de São Paulo sem a análise de variáveis relacionadas aos óbitos neonatais.

Um estudo sobre distribuição espacial da mortalidade neonatal e de fatores associados foi conduzido na cidade de Salvador, Nordeste do Brasil, de 2000 a 2006, revelando uma distribuição não aleatória da mortalidade e revelando o baixo peso ao nascer como o mais importante fator explicativo da variação espacial da mortalidade neonatal (Gonçalves et al., 2011).

O presente estudo corrobora essas pesquisas, demonstrando que a análise espacial da mortalidade perinatal pode contribuir significativamente para a identificação de áreas de risco. 
5.1 Mortalidade perinatal

Dentre as variáveis estudadas, a gravidez na adolescência foi associada tanto à mortalidade fetal, quanto à perinatal. Para a mortalidade neonatal precoce foram identificadas as variáveis: escolaridade baixa, gestante adulta, parto vaginal e idade gestacional entre 32 e 36 semanas.

Geralmente os estudos conduzidos sobre o tema dão enfoque à identificação de fatores de risco para a mortalidade perinatal, considerandose que tais óbitos apresentam fatores potencialmente redutíveis, principalmente aqueles relacionados à atenção à gestante, como assistência pré e perinatal, hábitos de vida, doenças maternas ou tipo de parto. Estudos conduzidos nas diversas regiões do Brasil mostram resultados distintos para os mesmos fatores (Menezes et al., 1998; Aquino et al., 2007; Goldenberg et al., 2005; Lanski et al., 2006; Magalhães et al., 2006). Devido às desigualdades sociais nas diferentes Regiões do País, o estudo local desses fatores pode possibilitar reduções mais significativas da mortalidade perinatal.

Quanto aos fatores biológicos maternos os estudos são controversos, sugerindo que estes possam ser menos relevantes do que determinados fatores socioeconômicos.

O aumento da gravidez na adolescência nos países em desenvolvimento tem despertado o interesse de pesquisadores e profissionais de saúde, tendo em vista a associação desse evento com 
piores resultados perinatais (Simões et al., 2003). Infelizmente existem muitas diferenças metodológicas nas pesquisas sobre este tema.

Um estudo desenvolvido no Ceará, no ano de 2000, considerou dois grupos de acordo com a idade materna: inferior a 16 anos (adolescentes precoces) e entre 16 e 19 anos (adolescentes tardias). Os autores concluíram que ambos os grupos, submetidos às mesmas condições socioeconômicas e de assistência pré-natal, apresentaram resultados semelhantes em relação à evolução da gestação, tendo características biológicas aceitáveis para um desempenho obstétrico satisfatório (Magalhães et al., 2006).

Outro estudo sobre gestação em adolescentes, realizado no Estado de Minas Gerais, mostrou resultados perinatais piores (maior frequência de prematuridade e baixo peso ao nascer) nas gestantes entre 10 e 14 anos de idade quando comparadas àquelas entre 15 e 19 anos (Goldenberg et al., 2005).

Dados mais recentes do Ministério da Saúde mostram ritmo de queda no número de partos na adolescência nos últimos anos na rede pública. Em adolescentes de 10 a 19 anos o número de partos diminuiu em $22,4 \%$ no período de 2005 a 2009. O Ministério da Saúde atribuiu essa tendência a campanhas governamentais destinadas aos adolescentes e à ampliação do acesso ao planejamento familiar (Brasil. Ministério da Saúde, 2010).

Alguns autores demonstram associação entre o risco de óbito perinatal e idade materna igual ou superior a 35 anos, além de outros fatores como baixo nível socioeconômico e maior proporção de óbitos fetais (Menezes et 
al., 1996; Menezes et al., 1998; Aquino et al., 2007). Em nosso estudo, como o número de gestantes nesta faixa etária foi muito pequeno, estas foram incluídas no grupo de gestantes adultas.

É importante salientar que mesmo em países desenvolvidos, como os Estados Unidos da América (EUA), com taxas mais baixas de mortalidade fetal, não houve declínio dos óbitos nas gestações de 20 a 27 semanas, apesar da diminuição destes nas gestações a partir de 28 semanas. Também foram identificados grupos com maiores taxas (mulheres negras, adolescentes, idade materna maior ou igual a 35 anos, sem companheiro, multíparas e com gestações múltiplas), bem como variação destas entre os Estados. As disparidades raciais e étnicas encontradas nas taxas de mortalidade fetal sugerem que nem todos os grupos se beneficiam igualmente dos avanços nas esferas sociais e médicas (MacDorman et al., 2007; MacDorman, 2011).

No presente trabalho, além da identificação de áreas de risco e das variáveis maternas e neonatais, foram analisados fatores socioeconômicos relacionados aos óbitos perinatais.

Desigualdades socioeconômicas regionais em relação à mortalidade perinatal têm sido evidenciadas no Brasil, sendo uma das principais explicações para as diferenças nas taxas de mortalidade infantil nas Regiões, nos Estados e municípios. Um estudo de coorte de 1982, em Pelotas, já mostrava mortalidade perinatal três vezes maior em famílias com baixa renda (Menezes et al., 1998). 
No presente estudo observamos correlação altamente significante entre o IPRS e os coeficientes de mortalidade perinatal e neonatal precoce ilustrando muito bem essa situação. Através da utilização do IPRS houve a possibilidade de sintetizar a situação de cada município em cinco grupos com características similares de riqueza municipal, longevidade e escolaridade.

No grupo 1 estão municípios localizados ao longo do principal eixo rodoviário (Rodovia Presidente Dutra) e dele fazem parte as cidades de Jacareí, São José dos Campos, Taubaté e Guaratinguetá, todos com os mais baixos coeficientes de mortalidade perinatal. Em 2002, nos 71 municípios do Estado que compunham o grupo 1 residiam 19 milhões de pessoas ( $50 \%$ da população estadual), tornando-o o maior dos cinco grupos em população. Fazem parte desse grupo grandes municípios paulistas (São Paulo, Campinas, São Bernardo do Campo, Sorocaba e Ribeirão Preto), além de importantes polos regionais (Presidente Prudente, São José do Rio Preto, Araçatuba, São Carlos e Araraquara). Os municípios desse grupo se caracterizam por um nível elevado de riqueza e bons indicadores sociais. Entretanto, são observadas disparidades significativas, não perceptíveis nos indicadores municipais agregados, que justificam trabalhos de investigação de padrões espaciais dentro de municípios maiores (Santos \& Noronha, 2001; Morais Neto et al., 2001).

No grupo 2 estão municípios que, embora tenham níveis de riqueza elevados, não são capazes de atingir bons indicadores sociais. São basicamente aqueles situados nas áreas metropolitanas do Estado, 
municípios que abrigam condomínios de alto padrão e municípios turísticos, como Campos do Jordão. Os resultados obtidos em nosso estudo indicam que os municípios de Campos do Jordão, Cruzeiro e Jambeiro, precisam de maior atenção quanto à assistência pré-natal, ao parto e ao recém-nascido, pois apresentam altas taxas de mortalidade perinatal, sendo relativamente mais ricos.

No grupo 3 encontram-se municípios com nível de riqueza baixo, mas com bons indicadores sociais. Uma das possíveis explicações para este comportamento é seu pequeno tamanho populacional, que poderia tornar mais transparentes e eficazes os instrumentos de política de descentralização em saúde e educação. Apenas a cidade de Monteiro Lobato, na Serra da Mantiqueira, encontra-se nesse grupo, com coeficiente de mortalidade de 18,8 .

O grupo 4 é composto por municípios com baixos níveis de riqueza e níveis intermediários de longevidade e/ou escolaridade. Estão incluídos municípios dispersos em todas as regiões do Estado, em especial nas áreas tradicionalmente consideradas problemáticas.

O grupo 5 é composto por localidades pobres, caracterizadas por baixos níveis de riqueza municipal, longevidade e escolaridade. Este grupo concentra os municípios mais desfavorecidos do Estado em áreas específicas: extremo leste do Vale do Paraíba, Vale do Ribeira e Pontal do Paranapanema.

Em nosso estudo todos os municípios do grupo 5 se encontram no terceiro e quarto quartis para mortalidade perinatal (19,8 a 40,9/1000 
nascimentos), com exceção das cidades de São Luis do Paraitinga e Canas. Entre os possíveis fatores para as melhores taxas nestas duas localidades podemos citar, respectivamente, a atenção perinatal da cidade de Taubaté e a abertura de uma Unidade de Cuidados Intensivos Neonatais na cidade de Lorena. Os demais municípios fazem parte do aglomerado na porção centro-oriental já citado anteriormente (Aparecida, Cunha, Lavrinhas, Piquete, Potim, Queluz, Roseira e Siveiras), mais as cidades de São Bento do Sapucaí e Santo Antonio do Pinhal (na Serra da Mantiqueira).

Observamos que a classificação dos grupos através do IPRS permitiu traçar um retrato do Vale do Paraíba, evidenciando a heterogeneidade regional para os indicadores estudados. Além disso, o IPRS também constitui um indicador útil para avaliar a eficácia das políticas públicas a cada dois anos.

A representação em box map permitiu visualizar municípios com altas taxas de mortalidade perinatal, cercados por vizinhos também com altas taxas e que correspondem a regiões com alta prioridade para intervenção do sistema de saúde. Estes municípios (Areias, Cruzeiro, Lavrinhas, Queluz e Silveiras) tiveram coeficiente médio de mortalidade perinatal de 25,2 e estão localizados no primeiro quadrante do diagrama de espalhamento de Moran.

Portanto, foi possível identificar microrregiões com maiores deficiências no atendimento pré-natal, na assistência ao parto e nos cuidados com o recém-nascido. Concomitantemente, observamos que a análise do IPRS nestes municípios mostrou correlação altamente significante entre mortalidade perinatal e variáveis socioeconômicas. 
5.2 Mortalidade fetal

Desde 1990, a mortalidade materna e perinatal vêm diminuindo em todos os países europeus, nos EUA e no Canadá. Atualmente as menores taxas estão na Europa, chegando a até 2,6/1000 nascimentos, e este cenário é atribuído à melhor assistência à mãe e ao feto antes e durante o parto, bem como à avaliação da qualidade dos serviços de obstetrícia em todos os hospitais (Galadanci et al., 2011; Mohangoo et al., 2011).

A distribuição espacial da mortalidade fetal na região estudada mostrou nove municípios com maiores coeficientes (12,1 a 26,0/1000 nascimentos), sendo três grupos de municípios que fazem fronteira (Roseira e Potim; Lavrinhas, Cruzeiro e Piquete; Bananal e São José do Barreiro) e dois municípios isolados (Jambeiro e Igaratá), e que nos municípios de Jacareí, Santa Branca, São José dos Campos, Taubaté, Lagoinha, Guaratinguetá, Canas, Areias e Arapeí foram encontrados os menores coeficientes (3,7 a 7,4/1000 nascimentos).

As cinco principais causas de mortalidade fetal são complicações intraparto, infecções maternas na gestação, doenças maternas (principalmente hipertensão arterial e diabetes), restrição de crescimento fetal e malformações congênitas (Oliveira et al., 2010; Cousens et al., 2011). Quase metade dos óbitos fetais ocorre no momento do parto, sendo diretamente relacionados à falta de cuidados qualificados para as gestantes e seus conceptos. Dois terços ocorrem na área rural, onde nem sempre há 
disponibilidade de obstetrizes qualificados (enfermeiros e médicos) para a assistência ao parto e para atender emergências obstétricas, incluindo o parto cesáreo (WHO, 2011). O treinamento desses profissionais através do Programa da Organização Mundial de Saúde "Essential Newborn Care" demonstrou redução desses óbitos (Carlo et al., 2010).

Em nosso estudo encontramos maior contribuição da variável gestante adolescente na mortalidade fetal. Alguns trabalhos sobre gravidez na adolescência demonstraram uma frequência aumentada de baixo nível socioeconômico, baixa escolaridade, menor atenção durante o pré-natal, parto prematuro, baixo peso ao nascer, morte materna e óbito perinatal neste grupo de gestantes (Bettiol et al., 1992; Ribeiro et al., 2000; Simões et al., 2003; Magalhães et al., 2006).

Entre doze países europeus que participaram do projeto EUROPERISTAT, houve diferenças substanciais nas taxas de mortalidade fetal, sendo identificados como fatores de risco as gestações múltiplas e a idade materna igual ou superior a 35 anos. Foi constatado que a associação entre idade materna e mortalidade fetal diminuiu, embora a prevalência de gestantes mais idosas na população tenha aumentado (Anthony et al., 2009).

MacDorman \& Kirmeyer (2009) analisaram os dados do National Vital Statistics System nos EUA e encontraram taxa de mortalidade fetal 2,2 vezes maior em adolescentes menores de 15 anos e $38 \%$ mais altas entre as adolescentes de 15 a 19 anos, quando comparadas às taxas de mulheres entre 25 e 29 anos, respectivamente. Os autores atribuíram esse risco 
aumentado às condições socioeconômicas desfavoráveis, salientando, entretanto, que a imaturidade biológica também contribui de forma significativa, particularmente entre adolescentes mais jovens.

Fonseca \& Coutinho (2010), em um estudo caso-controle, numa maternidade pública do município do Rio de Janeiro, encontraram relação conjugal estável e realização de pré-natal como fatores protetores e crescimento intrauterino restrito como fator predisponente ao óbito fetal. Não houve associação entre óbito fetal e gravidez na adolescência.

A associação entre mortalidade fetal e morbidade materna préexistente, idade gestacional $<37$ semanas e peso $<2500$ g, além de maior frequência da cor de pele preta ou parda foram destacados por Oliveira et al. (2010).

As pesquisas de gravidez na adolescência e mortalidade materna, fetal e perinatal apresentam muitas limitações metodológicas, como o pequeno tamanho das casuísticas, a ausência de uniformidade na faixa etária avaliada e a falta de controle sobre fatores capazes de interferir nos resultados perinatais. Estudos sobre grávidas adolescentes, geralmente incluem a população entre 15 a 19 anos. Poucas publicações envolvem adolescentes mais jovens e não há conclusões homogêneas em relação aos riscos associados à concepção nessa população.

Em nosso estudo não foi encontrada correlação entre mortalidade fetal e IPRS, sugerindo existir maior participação de fatores biológicos influenciando os coeficientes de mortalidade fetal nos municípios estudados, em relação aos fatores socioeconômicos. 
A análise espacial identificou Queluz, Lavrinhas, Cruzeiro e Bananal como municípios com alta prioridade para intervenção quanto à mortalidade fetal.

5.3 Mortalidade neonatal precoce

A distribuição espacial da mortalidade neonatal precoce mostrou nove municípios com altos coeficientes (12,48 a 22,78/1000 NV), sendo dois municípios vizinhos, dois isolados e um aglomerado composto de cinco municípios (Lavrinhas, Queluz, Silveiras, Areias e Cunha). Um padrão semelhante de mortalidade neonatal havia sido demonstrado no período de 1999 a 2001 por Nascimento et al. (2007) nesta região. Comparando a distribuição espacial da mortalidade neonatal precoce deste período (Nascimento et al., 2007) com os resultados do presente estudo constatamos que os municípios de Piquete, Queluz, Silveiras, Cunha e Campos do Jordão mantiveram seus altos coeficientes. Lavrinhas e Lagoinha melhoraram, mas continuam com altas taxas. Areias, Jambeiro e Santo Antonio do Pinhal (essas duas últimas já tinham altas taxas) pioraram seus valores. As cidades de Jacareí, Paraibuna, Guaratinguetá e Cachoeira Paulista melhoraram suas taxas.

Os valores mais baixos de mortalidade neonatal precoce (zero a 7,35/1000 NV) foram visualizados espacialmente em três blocos de 
municípios vizinhos e em dois municípios isolados. São os municípios do Vale do Paraíba histórico (Arapeí, Bananal e São José do Barreiro), Natividade da Serra, Paraibuna, Cachoeira Paulista, Guaratinguetá, Jacareí e São José dos Campos.

A correlação altamente significante entre o IPRS e os coeficientes de mortalidade neonatal precoce indica o importante papel das desigualdades socioeconômicas nas diferentes taxas deste componente da mortalidade infantil observadas na região do Vale do Paraíba. Grande parte dos municípios do grupo 5 do IPRS encontra-se no terceiro e quarto quartis para mortalidade neonatal precoce, com coeficientes de mortalidade entre 10,2 e 22,8/1000 NV. Destes, oito formam um aglomerado na porção centro-oriental da região e quatro estão isolados. No entanto três municípios com melhores condições de riqueza, escolaridade e longevidade (IPRS 2) também se encontram com altas taxas de mortalidade (municípios de Campos do Jordão, Cruzeiro e Jambeiro).

Os fatores socioeconômicos têm sido destacados em vários estudos sobre mortalidade neonatal. A análise espacial da mortalidade em recémnascidos com idade de 0 a 3 dias nos anos de 1995 e 1996 no município do Rio de Janeiro, evidenciou a presença de dois aglomerados com taxas elevadas em regiões de favelas, com maior proporção de mães adolescentes e chefe de família com rendimento até um salário mínimo (Andrade \& Szwarcwald, 2001).

Os indicadores renda e escolaridade que compõem o IPRS são destacados por vários autores que abordaram o papel das iniquidades 
socioeconômicas na mortalidade neonatal. Victora et al. (2010), analisando a qualidade dos cuidados de 4244 gestantes, mostraram que $98 \%$ delas tiveram assistência antenatal, porém o número de consultas foi maior naquelas com melhor situação econômica e de raça branca. A qualidade de atendimento foi significativamente melhor no setor privado. Na Holanda foi demonstrado que mulheres não holandesas e de baixa escolaridade iniciavam mais tardiamente o pré-natal (Alderliesten et al., 2007). Carvalho et al. (2007) identificaram a baixa escolaridade, número de consultas pré-natal inferior a três e raça preta ou parda como fatores de risco para a mortalidade neonatal.

Barros et al. (2008) mostraram associação significante entre o hospital de nascimento e a mortalidade neonatal, sugerindo que a assistência ao parto é a maior causa de variação das taxas entre os hospitais. Outros autores também demonstraram que o hospital de nascimento está associado a risco obstétrico, taxa de prematuridade e mortalidade neonatal precoce (Silva et al., 2009).

Os fatores de risco associados à mortalidade neonatal precoce, como baixa escolaridade, domicílio em favela, mãe sem companheiro e assistência pré-natal inadequada, representam categorias que refletem exclusão social e fatores psicossociais (Kilsztajn et al., 2003, Almeida \& Barros, 2004; Schoeps et al., 2007).

Em nosso estudo a variável gestação de 32 a 36 semanas esteve associada à mortalidade neonatal precoce. Esta observação está de acordo com vários autores, que destacam a prematuridade e o baixo peso ao 
nascer entre os principais fatores associados à mortalidade neonatal e infantil (Almeida \& Barros, 2004; Carvalho et al., 2007; Paulucci \& Nascimento, 2007; Barros et al., 2008; Jobim \& Aerts, 2008). Santos et al. (2008) em estudo de base populacional observaram que o pré-termo tardio (34 a $36^{6 / 7}$ semanas de gestação) apresenta risco de mortalidade neonatal e infantil, respectivamente, 5,1 e 2,1 vezes maior do que o recém-nascido de termo.

Quanto ao tipo de parto encontramos maior proporção de parto vaginal associado aos óbitos neonatais. Outros autores não encontraram diferença entre tipo de parto e mortalidade neonatal (Paulucci \& Nascimento, 2007) ou baixa vitalidade do recém-nascido avaliada pelo Apgar (Kilsztajn et al., 2007). Por outro lado, em uma série histórica (1995-2006) na Região Nordeste do Brasil, notou-se tendência de aumento na variável parto cesáreo como preditor de óbito neonatal (Vanderlei et al., 2010). A realização de cesárea eletiva tem sido associada à maior morbidade neonatal. De Luca et al. (2009) observaram aumento da mortalidade neonatal e da morbidade respiratória em recém-nascidos pré-termo tardios quando comparados aos neonatos de termo de parto vaginal.

No presente estudo observamos uma contribuição maior da variável gestante adulta, embora alguns estudos demonstrem a associação da gestação em adolescentes como fator de risco para baixo peso e óbito neonatal (Roth et al., 1998; Kilsztajn et al., 2003). Uma possível explicação para este comportamento seria a existência na região de centro especializado em gestação de alto risco. Em uma série histórica houve 
tendência de declínio da variável mãe adolescente como preditor de óbito neonatal (Vanderlei et al., 2010).

A representação em box map da mortalidade neonatal precoce permitiu visualizar os mesmos municípios com altos coeficientes identificados pelo diagrama de espalhamento para mortalidade perinatal, mais os municípios de Cunha e Santo Antonio do Pinhal, ambos com IPRS baixo (igual a 5) e Campos do Jordão e Lorena, com melhor índice de IPRS (igual a 2). Estes municípios representam regiões com maiores deficiências no atendimento pré-natal, na assistência ao parto e nos cuidados com o recém-nascido. Conforme já observado na mortalidade perinatal, a análise do IPRS nestes locais mostrou correlação entre mortalidade neonatal precoce e variáveis socioeconômicas.

Os resultados do presente estudo confirmaram nossa hipótese, mostrando variações nos coeficientes de mortalidade perinatal nos 35 municípios analisados. Em nossa opinião a Análise Espacial constitui um instrumento de grande utilidade e baixo custo, podendo ser recomendado para a programação de intervenções de saúde em áreas consideradas de alta prioridade. 
6. CONCLUSÕES 


\section{CONCLUSÕES}

A análise espacial da mortalidade perinatal no Vale do Paraíba, em São Paulo, Brasil, de 2004 a 2008, permitiu chegar às seguintes conclusões:

- A distribuição espacial identificou municípios com maiores coeficientes de mortalidade perinatal formando um aglomerado na porção oriental do Vale do Paraíba e municípios com menores coeficientes às margens da Rodovia Presidente Dutra, em direção a São Paulo.

- A análise global do coeficiente de mortalidade neonatal precoce demonstrou autocorrelação espacial entre os municípios, fato não observado quanto à mortalidade fetal e perinatal.

- Nos municípios com maiores coeficientes de mortalidade perinatal houve associação desta com a variável gestante adolescente.

- A distribuição espacial dos municípios segundo a sua classificação pelo Índice Paulista de Responsabilidade Social permitiu traçar um retrato do Vale do Paraíba, evidenciando a heterogeneidade regional para os indicadores estudados. Houve correlação entre o Índice 
Paulista de Responsabilidade Social e os coeficientes de mortalidade perinatal e neonatal precoce.

- As áreas de maior risco identificadas através dos mapas mostraram cinco municípios com alta prioridade para intervenção: Areias, Cruzeiro, Lavrinhas, Queluz e Silveiras. 
7. ANEXOS 


\section{ANEXO A}

Síntese das variáveis selecionadas e estrutura de pesos adotada, segundo

Dimensões do IPRS (SEADE, 2011)

\begin{tabular}{|c|c|c|}
\hline Dimensões & Componentes & $\begin{array}{l}\text { Contribuição para o } \\
\text { Indicador Sintético }\end{array}$ \\
\hline \multirow[t]{4}{*}{ Riqueza Municipal } & $\begin{array}{l}\text { Consumo residencial de } \\
\text { energia elétrica }\end{array}$ & $44 \%$ \\
\hline & $\begin{array}{l}\text { Consumo de energia } \\
\text { elétrica na agricultura, no } \\
\text { comércio e nos serviços }\end{array}$ & $23 \%$ \\
\hline & $\begin{array}{l}\text { Remuneração média dos } \\
\text { empregados com carteira } \\
\text { assinada e do setor } \\
\text { público }\end{array}$ & $19 \%$ \\
\hline & $\begin{array}{l}\text { Valor adicionado fiscal } \\
\text { per capita }\end{array}$ & $14 \%$ \\
\hline \multirow[t]{4}{*}{ Longevidade } & Mortalidade perinatal & $30 \%$ \\
\hline & Mortalidade infantil & $30 \%$ \\
\hline & $\begin{array}{l}\text { Mortalidade de pessoas } \\
\text { de } 15 \text { a } 39 \text { anos }\end{array}$ & $20 \%$ \\
\hline & $\begin{array}{l}\text { Mortalidade de pessoas } \\
\text { de } 60 \text { anos e mais }\end{array}$ & $20 \%$ \\
\hline \multirow[t]{4}{*}{ Escolaridade } & $\begin{array}{l}\text { Porcentagem de jovens } \\
\text { de } 15 \text { a } 17 \text { anos que } \\
\text { concluíram o ensino } \\
\text { fundamental }\end{array}$ & $36 \%$ \\
\hline & $\begin{array}{l}\text { Porcentagem de jovens } \\
\text { de } 15 \text { a } 17 \text { anos com pelo } \\
\text { menos quatro anos de } \\
\text { escolaridade }\end{array}$ & $8 \%$ \\
\hline & $\begin{array}{l}\text { Porcentagem de jovens } \\
\text { de } 18 \text { a } 19 \text { anos que } \\
\text { concluíram o ensino } \\
\text { médio }\end{array}$ & $36 \%$ \\
\hline & $\begin{array}{l}\text { Porcentagem de crianças } \\
\text { de cinco e seis anos que } \\
\text { frequentam a pré-escola }\end{array}$ & $20 \%$ \\
\hline
\end{tabular}

Fonte: Fundação Seade.Índice Paulista de Responsabilidade Social - IPRS 


\section{ANEXO B}

Critérios adotados para formação dos Grupos de Municípios. Edição 2002. (SEADE, 2011)

\begin{tabular}{|c|c|}
\hline Grupos & Categorias \\
\hline \multirow[t]{4}{*}{ Grupo 1} & Alta riqueza, alta longevidade e média escolaridade \\
\hline & Alta riqueza, alta longevidade e alta escolaridade \\
\hline & Alta riqueza, média longevidade e média escolaridade \\
\hline & Alta riqueza, média longevidade e alta escolaridade \\
\hline \multirow[t]{5}{*}{ Grupo 2} & Alta riqueza, baixa longevidade e baixa escolaridade \\
\hline & Alta riqueza, baixa longevidade e média escolaridade \\
\hline & Alta riqueza, baixa longevidade e alta escolaridade \\
\hline & Alta riqueza, média longevidade e baixa escolaridade \\
\hline & Alta riqueza, alta longevidade e baixa escolaridade \\
\hline \multirow[t]{4}{*}{ Grupo 3} & Baixa riqueza, alta longevidade e alta escolaridade \\
\hline & Baixa riqueza, alta longevidade e média escolaridade \\
\hline & Baixa riqueza, média longevidade e alta escolaridade \\
\hline & Baixa riqueza, média longevidade e média escolaridade \\
\hline \multirow[t]{4}{*}{ Grupo 4} & Baixa riqueza, baixa longevidade e média escolaridade \\
\hline & Baixa riqueza, baixa longevidade e alta escolaridade \\
\hline & Baixa riqueza, média longevidade e baixa escolaridade \\
\hline & Baixa riqueza, alta longevidade e baixa escolaridade \\
\hline Grupo 5 & Baixa riqueza, baixa longevidade e baixa escolaridade \\
\hline
\end{tabular}

Fonte: Fundação Seade.Índice Paulista de Responsabilidade Social - IPRS 


\section{ANEXO C}

Grupos IPRS - Municípios: Região Administrativa de São José dos Campos. Períodos (2000, 2002, 2004, 2006, 2008) (SEADE, 2011)

\begin{tabular}{|c|c|c|c|c|c|}
\hline Unidades Territoriais & $\begin{array}{c}\text { Grupo IPRS } \\
(2000)\end{array}$ & $\begin{array}{c}\text { Grupo IPRS } \\
\text { (2002) }\end{array}$ & $\begin{array}{c}\text { Grupo IPRS } \\
\text { (2004) }\end{array}$ & $\begin{array}{c}\text { Grupo IPRS } \\
(2006)\end{array}$ & $\begin{array}{c}\text { Grupo IPRS } \\
\text { (2008) }\end{array}$ \\
\hline Aparecida & 4 & 4 & 4 & 5 & 4 \\
\hline Arapeí & 4 & 4 & 4 & 4 & 4 \\
\hline Areias & 5 & 5 & 5 & 5 & 5 \\
\hline Bananal & 4 & 4 & 4 & 4 & 4 \\
\hline Caçapava & 1 & 2 & 2 & 2 & 2 \\
\hline Cachoeira Paulista & 4 & 5 & 5 & 4 & 5 \\
\hline Campos do Jordão & 2 & 2 & 2 & 2 & 2 \\
\hline Canas & 4 & 5 & 5 & 5 & 5 \\
\hline Cruzeiro & 4 & 4 & 2 & 2 & 2 \\
\hline Cunha & 5 & 5 & 5 & 5 & 5 \\
\hline Guaratinguetá & 2 & 2 & 1 & 1 & 2 \\
\hline Igaratá & 4 & 4 & 5 & 4 & 4 \\
\hline Jacareí & 2 & 2 & 1 & 1 & 1 \\
\hline Jambeiro & 2 & 1 & 1 & 2 & 2 \\
\hline Lagoinha & 5 & 4 & 4 & 4 & 4 \\
\hline Lavrinhas & 5 & 5 & 5 & 5 & 5 \\
\hline Lorena & 4 & 2 & 4 & 2 & 5 \\
\hline Monteiro Lobato & 4 & 3 & 4 & 3 & 3 \\
\hline Natividade da Serra & 5 & 4 & 5 & 4 & 4 \\
\hline Paraibuna & 5 & 4 & 4 & 4 & 4 \\
\hline Pindamonhangaba & 2 & 2 & 2 & 2 & 2 \\
\hline Piquete & 4 & 3 & 4 & 5 & 5 \\
\hline Potim & 5 & 5 & 5 & 5 & 5 \\
\hline Queluz & 5 & 5 & 5 & 5 & 5 \\
\hline Redenção da Serra & 4 & 5 & 4 & 4 & 4 \\
\hline Roseira & 4 & 5 & 5 & 5 & 5 \\
\hline Santa Branca & 4 & 4 & 4 & 5 & 4 \\
\hline Santo Antonio do & 5 & 5 & 5 & 5 & 4 \\
\hline São Bento do Sapucaí & 4 & 5 & 5 & 5 & 5 \\
\hline São Jose do Barreiro & 5 & 5 & 5 & 4 & 5 \\
\hline São Jose dos Campos & 1 & 1 & 1 & 1 & 1 \\
\hline São Luis do Paraitinga & 4 & 4 & 5 & 5 & 4 \\
\hline Silveiras & 5 & 5 & 5 & 5 & 5 \\
\hline Taubaté & 1 & 1 & 1 & 1 & 1 \\
\hline Tremembé & 4 & 4 & 5 & 5 & 5 \\
\hline
\end{tabular}

Fonte: Fundação Seade. 


\section{ANEXO F}

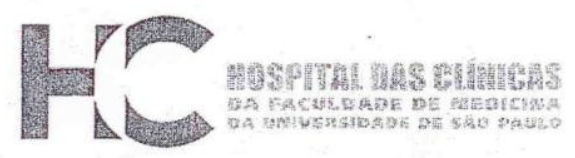

\section{APROVAÇÃO}

A Comissão de Ética para Análise de Projetos de Pesquisa CAPPesq da Diretoria Clínica do Hospital das Clínicas e da Faculdade de Medicina da Universidade de São Paulo, em sessão de 18/02/2009, APROVOU O Protocolo de Pesquisa n 0053/09, intitulado: "ANÁlISE ESPACIAL DA MORTALIDADE PERINATAL NO VALE DO PARAÍBA, SÃO PAULO-BRASIL (2003-2005)" apresentado pelo Departamento de PEDIATRIA.

Cabe ao pesquisador elaborar e apresentar à CAPPesq, os relatórios parciais e final sobre a pesquisa (Resolução do Conselho Nacional de Saúde $n^{\circ} 196$, de 10/10/1996, inciso IX.2, letra "c").

Pesquisador (a) Responsável: Profa Dra Vera Lúcia Jornada Krebs Pesquisador (a) Executante: Adriana de Oliveira Mukai

CAPPesq, 20 de Fevereiro de 2009

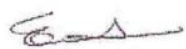

Prof. Dr. Eduardo Massad Presidente da Comissão de Ética para Análise de Projetos de Pesquisa 


\section{ANEXO G}

PRPPG-Pró-reitoria de Pesquisa e Pós-graduaçăo

Comitê de ética em Pesquisa

Rua Visconde do Rio Branco, 210 Centro Taubaté-SP 12020-040

Tel.: (12) $3625.4143-3635.1233 \quad$ Fax: (12) 3632.2947

cep@unitau.br

\section{DECLARAÇ̃̃O No ${ }^{\circ} 416 / 08$}

Protocolo CEP/UNITAU n ${ }^{\circ}$ 424/08 (Esse número de registro deverá ser citado pelo pesquisador nas correspondências referentes a este projeto)

Projeto de Pesquisa: Análise espacial da mortalidade perinatal no Vale do Paraíba, São Paulo Brasil (2003-2005).

Pesquisador(a) Responsável: Adriana de Oliveira Mukai

O Comitê de Ética em Pesquisa, em reunião de 12/12/2008, e no uso das competências definidas na Resolução CNS/MS 196/96, considerou o Projeto acima aprovado.

Taubaté, 12 de setembro de 2008

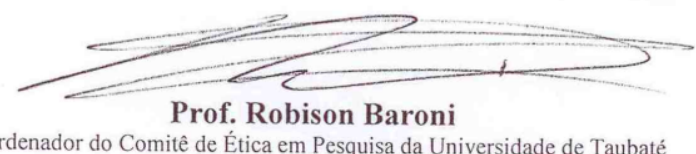

Coordenador do Comitê de Ética em Pesquisa da Universidade de Taubaté 
7. REFERÊNCIAS 


\section{REFERÊNCIAS}

Alderliesten ME, Vrijkotte TG, van der Wal MF, Bonsel GJ. Late start of antenatal care among ethnic minorities in a large cohort of pregnant women. BJOG. 2007;114(10):1232-9.

Almeida SDM, Barros MBA. Health care and neonatal mortality. Rev Bras Epidemiol. 2004;7(1):22-35.

Andrade CLT, Szwarcwald CL. Análise espacial da mortalidade neonatal precoce no Município do Rio de Janeiro, 1995-1996. Cad Saude Publica. 2001;17(5):1199-210.

Anthony S, Jacobusse GW, van der Pal-de Bruin KM, Buitendijk S, Zeitlin J; EURO-PERISTAT Working Group on Risk Factors. Do differences in maternal age, parity and multiple births explain variations in fetal and neonatal mortality rates in Europe?--Results from the EURO-PERISTAT project. Paediatr Perinat Epidemiol.. 2009; 23(4):292-300.

Aquino TA, Guimarães MJB, Sarinho SW, Ferreira LOC. Risk factors for perinatal mortality in Recife, Pernambuco State, Brazil, 2003. Cad Saude Publica. 2007;23(12):2853-61. 
Araújo BF, Bozzetti MC, Tanaka ACA. Mortalidade neonatal no município de Caxias do Sul: um estudo de coorte. J Pediatr (Rio de J). 2007;76(3):200-6.

Bailey TC, Gatrell AC. Interactive spatial data analysis. Essex: Longman Scientific \& Technical, 1995.

Barros AJ, Matijasevich A, Santos IS, Albernaz EP, Victora CG. Neonatal mortality: description and effect of hospital of birth after risk adjustment. Barros AJ, Matijasevich A, Santos IS, Albernaz EP, Victora CG. Rev Saúde Públ. 2008;42(1):1-9.

Barros FC, Victora CG, Vaughan JP. Causas de mortalidade perinatal em Pelotas, RS (Brasil). Utilização de uma classificação simplificada. Rev Saúde Públ. 1987;21(4):310-6.

Bettiol H; Barbieri MA; Gomes UA; Wen LY; Reis PM; Chiaratti TM; Vasconcellos V; Yamawaki RM. Atenção médica à gestação e ao parto de mães adolescentes. Cad Saude Publica. 1992;8(4):404-13. 
Referências

Brasil. Ministério da Saúde. A experiência brasileira em sistemas de informação em saúde. Brasília (DF): Ministério da Saúde; 2009. (Série B. Textos Básicos de Saúde; v.2). Disponível em: http://bvsms.saude.gov.br/bvs/publicacoes/experiencia brasileira sistemas saude volume2.pdf.

Brasil. Ministério da Saúde. Brasil acelera redução de gravidez na adolescência. Brasília (DF): Ministério da Saúde; 2010. Disponível em: http://portal.saude.gov.br/portal/aplicacoes/noticias/default.cfm?pg=dspDet alheNoticia\&id area $=124 \& C O$ NOTICIA $=11137$. .

Brasil. Ministério da Saúde. Coordenação Geral de Informações e Análises Epidemiológicas Painel de monitoramento da mortalidade infantil e fetal. Brasília (DF): Ministério da Saúde; 2012. Disponível em: http://svs.aids.gov.br/dashboard/mortalidade/infantil.show.mtw.

Brasil. Ministério da Saúde. Secretaria de Atenção à Saúde. Departamento de Ações Programáticas Estratégicas. Manual dos comitês de prevenção do óbito infantil e fetal. Brasília (DF): Ministério da Saúde; 2004. (Série A. Normas e Manuais Técnicos). Disponível em: http://2009.campinas.sp.gov.br/saude/dicas/manual obitos ms.pdf. 
Brasil. Ministério da Saúde. Secretaria de Vigilância em Saúde. Departamento de Ações Programáticas. Manual de vigilância do óbito infantil e fetal e do comitê de prevenção do óbito infantil e fetal. Brasília (DF): Ministério da Saúde; 2009. (Série A. Normas e Manuais Técnicos). Disponível em: http://portal.saude.gov.br/portal/arquivos/pdf/Manual Infantil Fetal.pdf.

Brasil. Ministério da Saúde. Secretaria de Vigilância em Saúde. Fundação Oswaldo Cruz. Introdução à Estatística Espacial para a Saúde Pública. Brasília (DF): Ministério da Saúde; 2007. (Série B. Textos Básicos de Saúde. Série Capacitação e Atualização em Geoprocessamento em Saúde; v.3). Disponível em: http://www.leb.fmvz.usp.br/ensino/manuais/capacitacao-e-atualizacao-emgeoprocessamento-em-saude-3.

Brasil. PNDU - Programa das Nações Unidas para o Desenvolvimento. Os objetivos de desenvolvimento do milênio: 8 objetivos para 2015. Brasília (DF): PNDU; 2000. Disponível em: http://www.pnud.org.br/ODM.aspx.

Camargo ECG. Análise de padrões de áreas [apostila]. In: Curso de Análise Espacial de Dados Geográficos. São José dos Campos (SP): INPE; 2000. p.1-32. 
Carlo WA, Goudar SS, Jehan I, Chomba E, Tshefu A, Garces A, Parida S, Althabe F, McClure EM, Derman RJ, Goldenberg RL, Bose C, Krebs NF, Panigrahi P, Buekens P, Chakraborty H, Hartwell TD, Wright LL; First Breath Study Group. Newborn-Care Training Perinatal Mortality in Developing Countries. N Engl J Med. 2010;362(7):614-23.

Carvalho MS. Aplicação de métodos de análise espacial na caracterização de áreas de riscos à saúde [tese]. Rio de Janeiro. COPPE, Universidade Federal do Rio de Janeiro; 1997. Disponível em: http://www.dpi.inpe.br/ miguel/cursoemilioribas/MaterialRef/marilia tese.pdf

Carvalho PI, Pereira PMH, Frias PG, Vidal SA, Figueiroa JN. Fatores de risco para mortalidade neonatal em coorte hospitalar de nascidos vivos. Epidemiol Serv Saúde. 2007:16(3):185-94.

Cliff AD, Ord JK. Spatial processes: models and applications. London: Pion; 1981.

Cousens S, Blencowe H, Stanton C, Chou D, Ahmed S, Steinhardt L, Creanga AA, Tunçalp O, Balsara ZP, Gupta S, Say L, Lawn JE. National, regional and worldwide estimates of stillbirth rates in 2009 with trends since 1995: a systematic analysis. Lancet. 2011;377(9774):1319-30. 
D’Orsi E, Carvalho MS. Perfil de nascimentos no município do Rio de Janeiro: uma análise espacial. Cad Saude Publica. 1998;14(2):367-79.

DATASUS. Departamento de Informática do SUS. Estatísticas vitais. Brasília (DF): Ministério da Saúde; 2008. Disponível em: $<$ http://www2.datasus.gov.br/DATASUS/index.php?area=0205>.

DATASUS. Departamento de Informática do SUS. Estatísticas vitais. Brasília (DF): Ministério da Saúde; 2011a. Disponível em: $<$ http://www2.datasus.gov.br/DATASUS/index.php?area=0205>

DATASUS. Departamento de Informática do SUS. Estatísticas vitais. Distrito Federal (DF): Ministério da Saúde; 2012. Disponível em: $<$ http://www2.datasus.gov.br/DATASUS/index.php?area=0205>.

DATASUS. Departamento de Informática do SUS. Painel de Indicadores da Situação de Saúde. Brasília (DF): Ministério da Saúde; 2011b. Disponível em http://svs.aids.gov.br/dashboard/situacao/saude.show.mtw

De Luca R, Boulvain M, Irion O, Berner M, Pfister RE. Incidence of early neonatal mortality and morbidity after late-preterm and term cesarean delivery. Pediatrics. 2009;123(6):e1064-71. 
Fonseca SC, Coutinho ESF. Fatores de risco para mortalidade fetal em uma maternidade do Sistema Único de Saúde, Rio de Janeiro, Brasil: estudo caso-controle. Cad Saude Publica. 2010;26(2):240-52.

Galadanci H, Kunzel W, Shittu O, Zinser R, Gruhl M, Adams S. Obstetric quality assurance to reduce maternal and fetal mortality in Kano e Kaduna State hospitals in Nigeria. Int J Gynaecol Obstet. 2011;114(1):23-8.

Goldenberg P, Figueiredo MCT, Silva RS. Gravidez na adolescência, prénatal e resultados perinatais em Montes Claros, Minas Gerais, Brasil. Cad Saude Publica. 2005;21(4):1077-86.

Gonçalves AC, Costa MCN, Braga JU. Análise da distribuição espacial da mortalidade neonatal e fatores associados em Salvador, Bahia, Brasil 2000-2006. Cad Saude Publica. 2011. 27(8):1581-92.

Jobim R, Aerts D. Avoidable infant mortality and associated factors in Porto Alegre, Southern Brazil, 2000-2003. Cad Saude Publica. 2008; 24(1):17987.

Kilsztajn S, Rossbach A, do Carmo MS, Sugahara GT. Prenatal care, low birth weight and prematurity in Brazil, 2000. Rev Saude Publica. 2003; 37(3):303-10 . 
Kilsztajn S, de Souza Lopes E, Nunes do Carmo MS, de Andrade Reyes AM. Apgar score associated wih mode of delivery in São Paulo State, Brazil. Cad Saude Publica. 2007; 23(8):1886-92.

Lansky S, França E, César CC, Monteiro Neto LC, Leal Mdo C. Mortes perinatais e avaliação da assistência ao parto em maternidades do Sistema Único de Saúde em Belo Horizonte, Minas Gerais, Brasil, 1999. Cad Saude Publica. 2006; 22(1):117-30.

Leal MC, Szwarcwald CL. Características da mortalidade neonatal no Estado do Rio de Janeiro na década de 80: Uma revisão espaço-temporal. Rev Saude Publica. 1997; 31(5):457-65.

Lima LP, Singer JM, Saldiva PHN. Análise espacial da violência urbana baseada em dados de pronto-socorro. Rev Saude Publica. 2008; 42(4):648-55.

MacDorman MF, Kirmeyer S. The challenge of fetal mortality. NCHS Data Brief. 2009;(16):1-8.

MacDorman MF. Race and ethnic disparities in fetal mortality, preterm birth and infant mortality in the United States: an overview. Semin Perinatol. $2011 ; 35(4): 200-8$. 
Magalhães MLC, Furtado FM, Nogueira MB, Carvalho FHC, Almeida FML, Mattar R, Camano L. Gestação na adolescência precoce e tardia - há diferença nos riscos obstétricos? Rev Bras Ginecol Obstet. 2006; 28(8):446-52.

Martin JA, Hamilton BE, Sutton PD, Ventura SJ, Menacker F, Munson ML. Births: Final Data for 2002. Natl Vital Stat Rep. 2003; 52(10)1-113.

Martins EF, Lana FCF, Maria E. Tendência da mortalidade perinatal em Belo Horizonte, 1984 a 2005. Rev Bras Enferm. 2010;63(3):446-51.

Matijasevich A, Santos IS, Barros FC. Does caffeine consuption during pregnancy increase the risk of fetal mortality? Cad Saude Publica. 2005; $21(6): 1676-84$

Menezes AMB, Barros FC, Victora CG, Alves C, Rocha C, Albernaz E, Menezes FS, Jannke HÁ. Mortalidade perinatal em duas coortes de base populacional no Sul do Brasil: tendências e diferenciais. Cad Saude Publica. 1996; 12(suppl1):33-41.

Menezes AMB, Barros FC, Victora CG, Tomasi E, Halpern R, Oliveira ALB. Fatores de risco para mortalidade perinatal em Pelotas, RS, 1993. Rev Saude Publica. 1998;32(3):209-16. 
Menezes AMB. Noções Básicas de Epidemiologia. In: Silva LCC, Menezes AMB. Epidemiologia das Doenças Respiratórias. Rio de Janeiro: Revinter; 2001. v.1. p.1-24.

Mohangoo AD, Buitendijk SE, Szamotulska K, Chalmers J, Irgens LM, Bolumar F, Nijhuis JG, Zeitlin J; Euro-Peristat Scientific Committee. Gestational age patterns of fetal and neonatal mortality in Europe: results from the Euro-Peristat project. PLoS One. 2011;6(11):e24727.

Morais Neto OL, Barros MBA, Martelli CMT, Silva AS, Cavenaghi SM, Siqueira Jr JB. Diferenças no padrão de ocorrência de mortalidade neonatal e pós-natal no município de Goiânia, Brasil, 1992-1996: análise espacial para identificação de áreas de risco. Cad Saude Publica. $2001 ; 7(5): 1241-50$.

Mukai AO, Alves KSC, Nascimento LFC. Análise espacial das internações por pneumonia na região do Vale do Paraíba (SP). J Bras Pneumol. 2009; 35(8):753-8.

Nascimento LFC, Batista GT, Dias NW, Catelani CS, Becker D, Rodrigues L. Análise espacial da mortalidade neonatal no Vale do Paraíba, 1999 a 2001. Rev Saúde Públ. 2007;41(1):94-100. 
MacDorman MF, Munson ML, Kirmeyer S. Fetal and perinatal mortality, United States, 2004. Natl Vital Stat Rep. 2007; 56(3):1-19

Nascimento LFC, Medeiros APP. Admissions due to pneumonia and biomass burning: a spatial approach. J Pediatr (Rio J). 2012; 88(2):177-83.

Oliveira EFV, Gama SGN, Silva CMFP. Gravidez na adolescência e outros fatores de risco para mortalidade fetal e infantil no Município do Rio de Janeiro, Brasil. Cad Saude Publica. 2010; 26(3):567-78.

Paulucci RS, Nascimento LFC. Neonatal mortality em Taubaté, São Paulo, Brazil: a case-control study. Rev Paul Pediatr. 2007; 25(4):358-63.

Ribeiro ERO, Barbieri MA, Bettiol H, Silva AAM. Comparação entre duas coortes de mães adolescentes em município do Sudeste do Brasil. Rev Saúde Públ. 2000;34(2):136-42.

Roth J, Hendrickson J, Schilling M, Stowell DW. The risk of teen mothers having low birth weight babies: implications of recent medical research for school health personnel. J Sch Health. 1998; 68(7):271-5. 
Santos IS, Matijasevich A, Silveira MF, Sclowitz IK, Barros AJ, Victora CG, Barros FC. Associated factors and consequences of late preterm births: results from the 2004 Pelotas birth cohort. Paediatr Perinat Epidemiol. $2008 ; 22(4): 350-9$

Santos SM, Noronha CP. Padrões espaciais de mortalidade e diferenciais sócio-econômicos na cidade do Rio de Janeiro. Cad Saude Publica. 2001; 17(5):1099-110.

Sarinho WS, Djalma Filho AM, SIlva GAP, Lima MC. Fatores de risco para óbitos neonatais no Recife; um estudo caso-controle. J Pediatr (Rio de J). 2001; 77(4):294-8.

Schoeps D, Almeida MF, Alencar GP, França Junior I, Novaes HMD, Siqueira AAF, Campbell O, Rodrigues LC. Fatores de risco para mortalidade neonatal precoce . Rev Saúde Públ. 2007; 41(6):1013-22.

SEADE. O índice paulista de responsabilidade social. São Paulo: SEADE; 2011. Disponível em: http://www.seade.gov.br/projetos/iprs/.

Silva ZP, Almeida MF, Ortiz LP, Alencar GP, Alencar AP, Schoeps D, Minuci EG, Novaes HMD. Características dos nascidos vivos, das mães e mortalidade neonatal precoce na Região Metropolitana de São Paulo, Brasil. Cad Saude Publica. 2009;25(9):1981-9. 
Simões VMF, Silva AAM, Bettiol H, Lamy-Filho F, Tonial SR, Mochel EG. Características da gravidez na adolescência em São Luis, Maranhão. Rev Saúde Públ. 2003;37(5):559-65.

TerraView 3.1.3. São José dos Campos (SP): INPE, 2006. Disponível em: www.dpi.inpe.br/terraview.

TerraView 4.0.0. São José dos Campos (SP): INPE, 2010. Disponível em: www.dpi.inpe.br/terraview.

UNICEF. Situação Mundial da Infância 2008: sobrevivência infantil. Brasília (DF): UNICEF; 2007. Disponível em http://www.unicef.org/brazil/pt/sowc2008 br.pdf.

UNICEF. Situação mundial da infância: saúde materna e neonatal. Nova York: UNICEF; 2009. Disponível em http://www.unicef.pt/docs/situacao mundial da infancia 2009.pdf.

Vanderlei LCM, Simões FTPA, Vidal AS, Frias PG. Avaliação de preditores do óbito neonatal em uma série histórica de nascidos vivos no Nordeste brasileiro. Rev Bras Saude Matern Infant. 2010;10(4):449-58. 
Victora CG, Matijasevich A, Silveira M, Santos I, Barros AJ, Barros FC. Socio-economic and ethnic group inequities in antenatal care quality in the public and private sector in Brazil. Health Policy Plan. 2010;25(4):253-61.

Woods R. Long-term trends in fetal mortality: implications for developing countries. Bull World Health Organ. 2008;86(6):460-6.

World Health Organization. 2.6 million stillbirths in 2009: new global and country estimates published in Lancet Series and World Health Statistics. Geneva: $\quad$ WHO; 2011.2 Disponível em http://www.who.int/maternal child adolescent/news events/news/2011/still births 20110414/en/

World Health Organization. Neonatal and perinatal mortality: country, regional and global estimates. Geneva: WHO; 2006. Disponível em http://whqlibdoc.who.int/publications/2006/9241563206 eng.pdf. 